\title{
Quantifying Arctic contributions to climate predictability in a regional coupled ocean-ice-atmosphere model
}

\author{
Ralf Döscher · Klaus Wyser · H. E. Markus Meier • \\ Minwei Qian · René Redler
}

Received: 19 November 2008/ Accepted: 19 March 2009/Published online: 8 April 2009

(c) The Author(s) 2009. This article is published with open access at Springerlink.com

\begin{abstract}
The relative importance of regional processes inside the Arctic climate system and the large scale atmospheric circulation for Arctic interannual climate variability has been estimated with the help of a regional Arctic coupled ocean-ice-atmosphere model. The study focuses on sea ice and surface climate during the 1980s and 1990s. Simulations agree reasonably well with observations. Correlations between the winter North Atlantic Oscillation index and the summer Arctic sea ice thickness and summer sea ice extent are found. Spread of sea ice extent within an ensemble of model runs can be associated with a surface pressure gradient between the Nordic Seas and the Kara Sea. Trends in the sea ice thickness field are widely significant and can formally be attributed to large scale forcing outside the Arctic model domain. Concerning predictability, results indicate that the variability generated by the external forcing is more important in most regions than the internally generated variability. However, both are in the same order of magnitude. Local areas such as the
\end{abstract}

R. Döscher $(\bowtie) \cdot$ K. Wyser

Rossby Centre, SMHI (Swedish Meteorological

and Hydrological Institute), Folkborgsvägen 1,

60176 Norrköping, Sweden

e-mail: ralf.doescher@smhi.se

H. E. M. Meier

SMHI (Swedish Meteorological and Hydrological Institute),

Folkborgsvägen 1, 60176 Norrköping, Sweden

M. Qian

UQAM (Université du Québec à Montréal),

Ouranos, 550, Sherbrooke Ouest, 19 tage,

Montreal, QC H3A 1B9, Canada

R. Redler

NEC Laboratories Europe, Rathausallee 10,

53757 Sankt Augustin, Germany
Northern Greenland coast together with Fram Straits and parts of the Greenland Sea show a strong importance of internally generated variability, which is associated with wind direction variability due to interaction with atmospheric dynamics on the Greenland ice sheet. High predictability of sea ice extent is supported by north-easterly winds from the Arctic Ocean to Scandinavia.

Keywords Arctic - Predictability - Coupled model · Regional model

\section{Introduction}

Prediction of the Arctic climate system is a pressing need on the agenda of model development and system understanding. Currently, global climate models (GCMs) are used to carry out climate scenario runs that are basically long term projections of possible future climates under different emission scenarios. For the Arctic, climate projections are superimposed by oscillations of annual to decadal time scale (e.g. Zhang and Walsh 2006). These simulated oscillations often represent natural processes, but cannot be timed correctly in current GCM simulations, due to insufficient initialization of the states of cryosphere and ocean circulation (Sorteberg et al. 2005), and due to intrinsic random variability. Thus, there is a strongly reduced forecast skill on annual and decadal scales in long GCM integrations. This problem has been highlighted recently by the observed extremely low Arctic sea ice extent during late summer 2007 (documented e.g. by the US National Snow and Ice Data Center (NSIDC) at http://nsidc.org/news/ press/2007_seaiceminimum), which was not expected. The IPCC (2007) is not projecting such a low ice cover before 2030. Individual IPCC ensemble member models generate 
rapid change events of similar amplitude not earlier than 2013 (Holland et al. 2006). Full decadal, annual or seasonal Arctic forecast systems (other than empirical or statistical efforts focussing on sea ice extent, collected under the Sea Ice Outlook effort: http://www.arcus.org/search/seaiceoutlook/) are not available.

The IPCC effort led to a best estimate of future climate development. The societal and political response includes the development of strategies for adaptation to changing climate. Adaptation research and related climate change impact studies define the need for decadal forecasts. For the Arctic area, this requires knowledge on decadal predictability, i.e. on the theoretical and practical possibility to develop skilled decadal forecast systems. Despite the highly non-linear nature of the climate system, seasonal to multi-annual forecasts of mean states are theoretically possible due to forcing by system components with longer timescales, such as the oceanic heat storage. Examples for mechanisms supporting multi-annual predictions are a feedback of the Labrador Sea water production in response of Arctic sea ice export (Koenigk et al. 2006) and sustainability in near surface water heat content (Sutton and Allen 1997; Keenlyside et al. 2008).

Predictability of the climate system or its components can be assessed by analysis of ensemble simulations, i.e. a number of numerical simulations of a system under identical or at least similar forcing conditions. The science of decadal prediction is in its very beginning and several studies concerning prediction capability of existing simulation systems have been carried out: Sorteberg et al. (2005) use a fivemember ensemble of a global coupled ocean-atmosphere-ice model initialized with different states of the ocean overturning circulation. Wang et al. (2007) evaluate 63 realizations of 20 coupled GCMs to comparatively analyse the character and timing of different Arctic warming periods. These valuable types of studies cover global scale processes and its local effects. A limitation is given by their capability to attribute regional phenomenon to either global or regional processes. To understand the nature and relative importance of these different processes on different scales it is crucial to further develop the science of decadal prediction in the Arctic. Increased understanding gives important guidance for future development efforts. A strait forward way to overcome current limitations of GCMs is to utilize regional climate models (RCMs) with prescribed lateral boundary conditions in addition to GCMs.

Rinke and Dethloff (2000) did a first step by running ensembles based on a regional Arctic atmosphere-standalone model. Uncertainties in results were shown to arise from initial conditions, lower boundary conditions and from internal processes. The latter were of the same order as uncertainty due to inaccurate physical parameterizations. A next step towards regional assessment of processes and variability relevant for interannual and decadal prediction was taken by Mikolajewicz et al. (2005), who utilized a global ocean-ice model regionally coupled to an Arctic atmosphere model to generate an ensemble of four simulations. It was shown that both large scale and internal Arctic processes contributes to sea ice export events. Bifurcations within the model ensemble are found with respect to Labrador Sea salinity.

In this work we focus on the Arctic region and use a pure regional coupled system consisting of a regional ocean-ice model coupled to a regional atmosphere model. Thus we can better distinguish variability arising from Arctic-internal processes and externally forced variability. We address the conditions for predictability of the Arctic climate system by analyzing interannual variability in the Arctic, under the condition that the large scale circulation in ocean and atmosphere outside the Arctic area is given. A major question in this setup is to what extent the Arctic interannual variability is determined by the Arctic itself. The total Arctic natural variability is a combination of variability originating from outside the Arctic by a varying large scale circulation, and variability generated inside the Arctic triggered by a nonlinear chaotic interplay of internal ocean, sea ice and atmosphere processes. We utilize a regional coupled model of a PanArctic domain for carrying out repeated runs from slightly disturbed initial conditions. Several such runs constitute an ensemble of model simulations, which allows for analysis of internally generated versus externally forced variability.

Strong sensitivity to small disturbances in initial conditions, which is characterizing non-linear variability, can lead to model simulations of quite different possible circulation and ice conditions under identical large scale forcing. These differences can be expressed in terms of potential predictability (Zwiers 1987; Pohlmann et al. 2004), which is defined here as the extent to which variability of Arctic variables can potentially be controlled by external forcing. High sensitivity of internal processes to small disturbances is always limiting prediction possibilities. By keeping the external forcing, i.e. the large scale forcing identical for all ensemble members, we can approach the limits of Arctic potential predictability.

In the following section we give a description of the model tool referring to more detailed descriptions elsewhere. Thereafter we describe a model ensemble of four members, give a brief model validation of ensemble mean quantities and report about results related to model spread and predictability of ice and near-surface variables. In the final section, results are summarized and discussed.

\section{The RCAO model}

Our modelling tool for regional Arctic simulations is the Rossby Centre Atmosphere Ocean model RCAO, which 
consists of the component models RCA (atmosphere) and RCO (ocean). The first version of RCAO has been developed for regional coupled climate scenario runs for Northern Europe (Döscher et al. 2002). A further developed version is described here in an Arctic set-up covering a wider Arctic domain from about $50^{\circ} \mathrm{N}$ in the Atlantic sector to the Aleutian Islands in the North Pacific as described in Fig. 1. Both RCO and RCA run in a horizontal resolution of $0.5^{\circ}$ on a rotated latitude-longitude grid with the grid equator crossing the geographical North Pole. The domain has been chosen to get suitable boundary data for the ocean, to avoid orographical obstacles within the atmosphere models boundary zone and to cover wind forcing variability in the Bering Sea.

The ocean component $\mathrm{RCO}$ is a full-featured $3 \mathrm{D}$ primitive equation ice-ocean model in geopotential vertical coordinates and with a free surface (Webb et al. 1997). It has been thoroughly described and validated for a Baltic Sea domain (Meier et al. 2003). RCO incorporates a dynamic-thermodynamic sea ice model based on an elastic-viscous-plastic (EVP) rheology (Hunke and Dukowicz 1997) and a Semtner-type thermodynamics (Semtner 1976). The present version includes a rotated latitude-longitude grid and a two-equation turbulence closure $\kappa-\varepsilon$ scheme (Rodi 1980) for vertical mixing. In the present study we use an Arctic domain with 59 unevenly spaced vertical levels. The topography is interpolated from the
ETOPO5 (1988) dataset. A closed lateral boundary exists at the Aleutian island chain and an open lateral boundary condition according to Stevens (1990) is implemented in the North Atlantic Ocean. In the case of inflowing water, climatological monthy mean data of the PHC dataset (Steele et al. 2001) are used. Further forcing is provided by the volume flux of 19 major rivers discharging into the Arctic ocean (Prange 2003). The PHC climatology for salinity is also used for restoring sea surface salinity on a timescale of 240 days. This type of restoring is necessary to prevent artificial salinity drift due to insufficient description of freshwater runoff and precipitation. The ice and snow albedo formulation is based on a modified version of Køltzow (2007) with albedo values dependent on the ice surface temperature. A parameterization for melt ponds is included:

$$
\begin{aligned}
& \alpha_{\text {seaice }}=0.84 \quad \text { if }\left(T_{S} \leq-2^{\circ} \mathrm{C}\right) \\
& \alpha_{\text {seaice }}=0.84-0.1\left(2+T_{S}\right) \quad \text { if }\left(-2^{\circ} \mathrm{C} \leq T_{S}<0^{\circ} \mathrm{C}\right) \\
& \alpha_{\text {seaice }}=0.51 \quad \text { if }\left(T_{S} \geq 0{ }^{\circ} \mathrm{C}\right) \\
& \Delta_{\text {meltpond }}=0.11\left(2+T_{S}\right) \quad \text { if }\left(T_{S} \geq-2^{\circ} \mathrm{C}\right) \\
& \alpha_{\text {meltpond }}=0.36-0.1\left(2+T_{S}\right) \quad \text { if }\left(T_{S} \geq-2^{\circ} \mathrm{C}\right) \\
& \alpha_{\text {surface }}=\left(1-\Delta_{\text {meltpond }}\right) \times \alpha_{\text {seaice }}+\Delta_{\text {meltpond }} \times \alpha_{\text {meltpond }}
\end{aligned}
$$

$\alpha$ represents different surface albedos, $T_{S}$ the ice surface temperature and $\Delta_{\text {meltpond }}$ the meltpond fraction. The
Fig. 1 Model domain and bottom topography (in $\mathrm{m}$ )

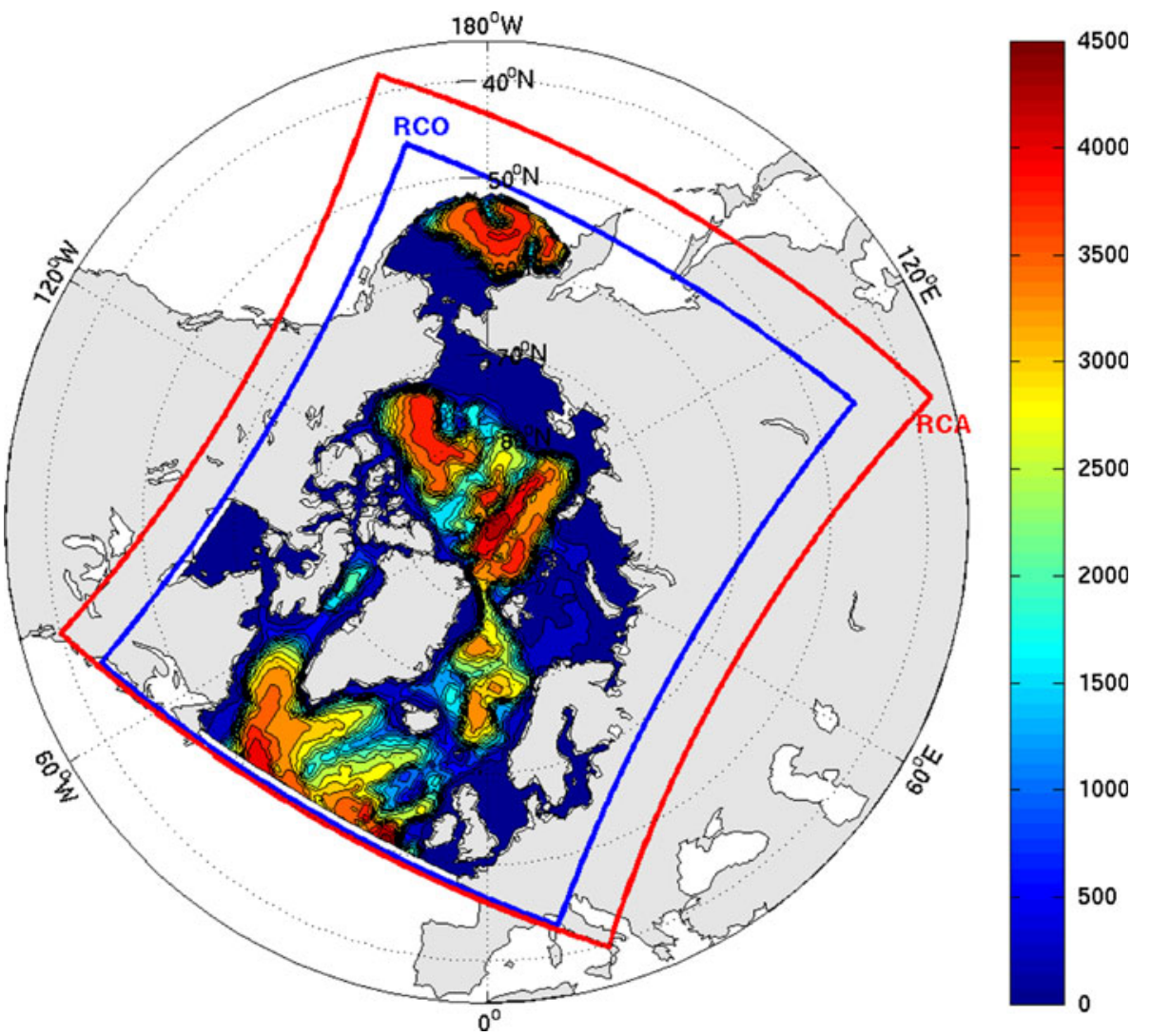


original formulation has been developed for central Arctic conditions of the Sheba ice drift station in 1997-1998.

The atmosphere component RCA has been described by Jones et al. (2004a, b) and Kjellström et al. (2005). RCA builds on the high resolution limited area model (HIRLAM) (Undén et al. 2002) that is operationally used for weather forecasts. The current model setup has 24 vertical layers in terrain-following hybrid coordinates with a model top at approximately $15 \mathrm{hPa}$. The lateral boundary forcing is taken from the ERA-40 reanalysis (Uppala et al. 2005) and updated with a 6-hourly frequency. Recent improvements of RCA, included in the present setup, are better parameterizations for turbulence, microphysics, and radiation (for details see Kjellström et al. 2005). The land surface model has been replaced with a completely new scheme (Samuelsson et al. 2006) that responds faster to changes in the atmosphere, thus addressing some of the shortcomings of the previous RCA version. It also includes a more sophisticated treatment of the snow cover over land that accounts for the packing and darkening of snow with age.

In the coupled set-up, sea surface temperature (SST), sea ice concentration, ice temperature and snow/ice albedo are obtained from RCO through a coupler. In the RCA areas not covered by the RCO domain (e.g. ocean range south of the Aleutian islands), the first three variables are read from the ERA-40 reanalysis and updated every $6 \mathrm{~h}$. In these areas snow on sea-ice is treated prognostically similar to the treatment of snow over land. In this case, the heat flux through the sea-ice assumes an ice thickness of $2 \mathrm{~m}$ everywhere and water temperature of $-1.8^{\circ} \mathrm{C}$ at the bottom of sea-ice.

Both models RCO and RCA run in parallel and exchange information via a separate coupler software OASIS4 (Valcke and Redler 2006) with a coupling frequency of three hours. The ocean provides surface state variables and the atmosphere returns fluxes of heat (including radiation), freshwater and momentum. State variables are taken from the last ocean time step before coupling and serve as lower boundary data during the following atmospheric time steps until the next coupling event. The atmosphere-to-ocean fluxes are averaged over one coupling time step and then passed to the ocean, where the fluxes are used throughout the following coupling time step. The coupling time step of three hours is sufficiently short to resolve the daily cycle and to resolve the thermodynamic interaction processes between atmosphere and sea ice.

Initialization of atmospheric and oceanic fields is done in different ways. RCA is run a few time steps for dynamic adjustment of an initial field interpolated from the ERA-40 forcing data onto the RCA grid. For the present model experiments starting in April 1959, initial fields for RCO are taken from the PHC climatology (Steele et al. 2001). The coupled model RCAO is then run through the ERA-40 period up to the year 2001 (Spin-up run 1 in Table 1). Typically, the development of Arctic sea ice extent shows a spin-up phase of about 20 years. After the late 1970s the simulated sea ice extent is close to the interannual average of observations (Fig. 2). After the first 42 years of integration the coupled ocean and ice can be expected in quasiequilibrium, i.e. dynamically adjusted to the model and in agreement with the advective regime. The resulting ocean and sea ice fields are then transferred back to 1959. This 2nd set of start conditions give generally improved ice extent during the first about 20 years in a second spin-up run (spin-up run 2 in Table 1). Still the resulting ocean initial fields are not adjusted to the real conditions of the year 1959, which leads to an inability to cover multiyear variability before the end of the 1970s. Therefore, only model data from after 1979 are used for model validation and analysis.

\section{An ensemble of coupled hindcast runs}

After two spin-up runs as described in Sect. 2 and listed in Table 1, we have carried out four production runs with our regional coupled model RCAO, covering the years 19602000 and all starting from the spin-up run 2 as indicated in Table 1. All coupled runs (predictability runs P1-P4) were forced at the lateral boundaries with data from the ERA-40

Table 1 Runs of the regional coupled Arctic model RCAO

\begin{tabular}{lll}
\hline Run no. & Name & Description \\
\hline 1 & Spinup 1 & Start 1959 from temperature, salinity climatology, 2.3 m constant ice thickness \\
2 & Spinup 2 & Start in 1959, from spin-up run 1, state of year 2000 \\
3 & P1 & Start in 1959, from spin-up run 2, state of year 2000 \\
4 & P2 & Start in 1959, from spin-up run 2, state of year 2000, initial disturbance 10\% \\
5 & P3 & Start in 1959, from spin-up run 2, state of year 2000, initial disturbance 15\% \\
6 & P4 & Start in 1959, from spin-up run 2, year state of 2000, initial disturbance 20\% \\
\hline
\end{tabular}

All runs start on April 1st. Initial disturbances refer to sea ice concentration at the North Pole 
Fig. 2 Spin-up: timeseries of Arctic (a) sea ice extent and (b) summer sea ice extent. Black reference curves originates from the ERA-40 reanalysis (dash-dotted, Rayner et al. 2003), adjusted for the RCAO model domain
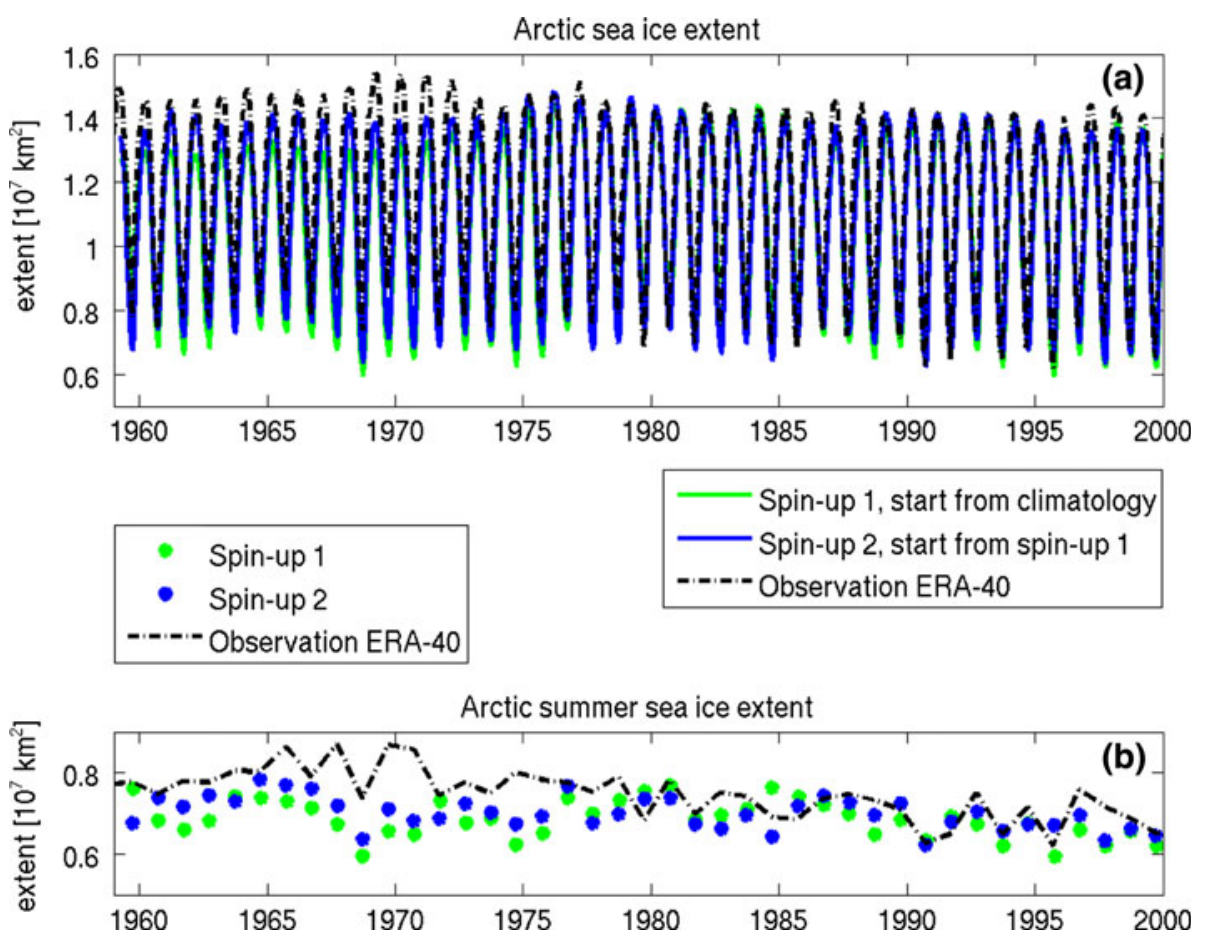

reanalysis. The model runs $\mathrm{P} 1-\mathrm{P} 4$ differ only in their initialization. Run P1 is directly started in April 1959 using ocean and sea ice state from April of year 2000. The runs P2-P4 differ by slight modifications of the initial sea ice concentration by $10 \%(\mathrm{P} 2), 15 \%(\mathrm{P} 3)$ and $20 \%(\mathrm{P} 4)$ in a single model grid box at the North Pole. No other modifications are made. These four simulations constitute an ensemble. Differences between the four ensemble members develop due to non-linear interaction within the coupled ocean-ice-atmosphere system. We argue that the location of the initial disturbance is not important for the results as long as it is small. We confirm that after a few days of coupled interaction, the initial disturbance is spread out all over the Arctic sea ice area (no figure shown here).

Before analyzing the differences and similarities of these runs (next section), which is the major subject of this paper, we test the hindcast performance of the ensemble as a whole for selected key parameters, such as sea ice concentration, sea ice extent and its relation to the large scale atmospheric circulation.

Summer sea ice extent anomalies (annual minimum extent during September) between 1980 and 2000 are shown in Fig. 3c. The simulations are compared with the anomalies of satellite observations (Cavalieri et al. 2003) and the ERA-40 reanalysis product (Sea ice extent in ERA40 originates from the gridded observational Hadley Centre Ice and SST data set HadISST1 (Rayner et al. 2003)). The ERA-40 and model simulations show similar oscillations and trends. All ensemble members show a decreasing trend of sea ice extent after 1979. Three out of four simulated trends are very close to the observed trend of Cavalieri et al. (2003). That group gives a combined trend of $-439,000 \mathrm{~km}^{2} / 10$ years. When the fourth member is included, this results in $-359,000 \mathrm{~km}^{2} / 10$ years. The trend based on Cavalieri et al. (2003) is $-400,000 \mathrm{~km}^{2} / 10$ years. The differences within the group of three runs are smaller than the observational uncertainty as indicated by the difference between the two observations. The majority of ensemble members are well capable of resembling the decreasing trend even quantitatively.

A coupled climate model is not expected to resemble year-to-year variability of any climate variable in the correct phase for individual years, neither globally nor regionally. Such a capability depends on the size of the model domain and the importance and predictability of internal processes. Smaller model domains covering parts of the Arctic (such as used for the Arctic Regional Model Intercomparison Project ARCMIP (Rinke et al. 2000)) are suited for in-phase realistic interannual variability if forced realistically at the lateral boundaries. Larger pan-Arctic domains such as the one of RCAO allow for internal nonlinear hardly predictable processes to grow. Compared to standalone component models (ocean-ice only or atmosphere-only) a coupled system is less constrained by surface forcing, and thus free to develop its own inherent regional dynamics. Still, our model runs show a rough qualitative agreement with the up and down swings of the observed summer sea ice extent (Fig. 3c). Correlation coefficients between observed and simulated summer sea ice extent anomalies vary between 0.34 and 0.70 . 
Fig. 3 a Time series of winter (JFM) NAO as sea level pressure difference from the RCAO ensemble mean (red line, for more details see text), ERA-40 reanalysis (black line, pressure difference, see text) and Climate Prediction Center NAO index multiplied by 10 (blue line). See more information in the text. b Intraensemble standard deviation of Arctic summer minimum sea ice extent anomaly. c Arctic summer minimum sea ice extent anomaly for the period 1980 2000. Ensemble simulations and trends are depicted in red and observations (Rayner et al. (2003) full lines, Cavalieri et al. (2003) dotted lines) are depicted in black. All observed extent values are adjusted to the regional RCAO domain, i.e. sea ice outside the RCO domain is omitted
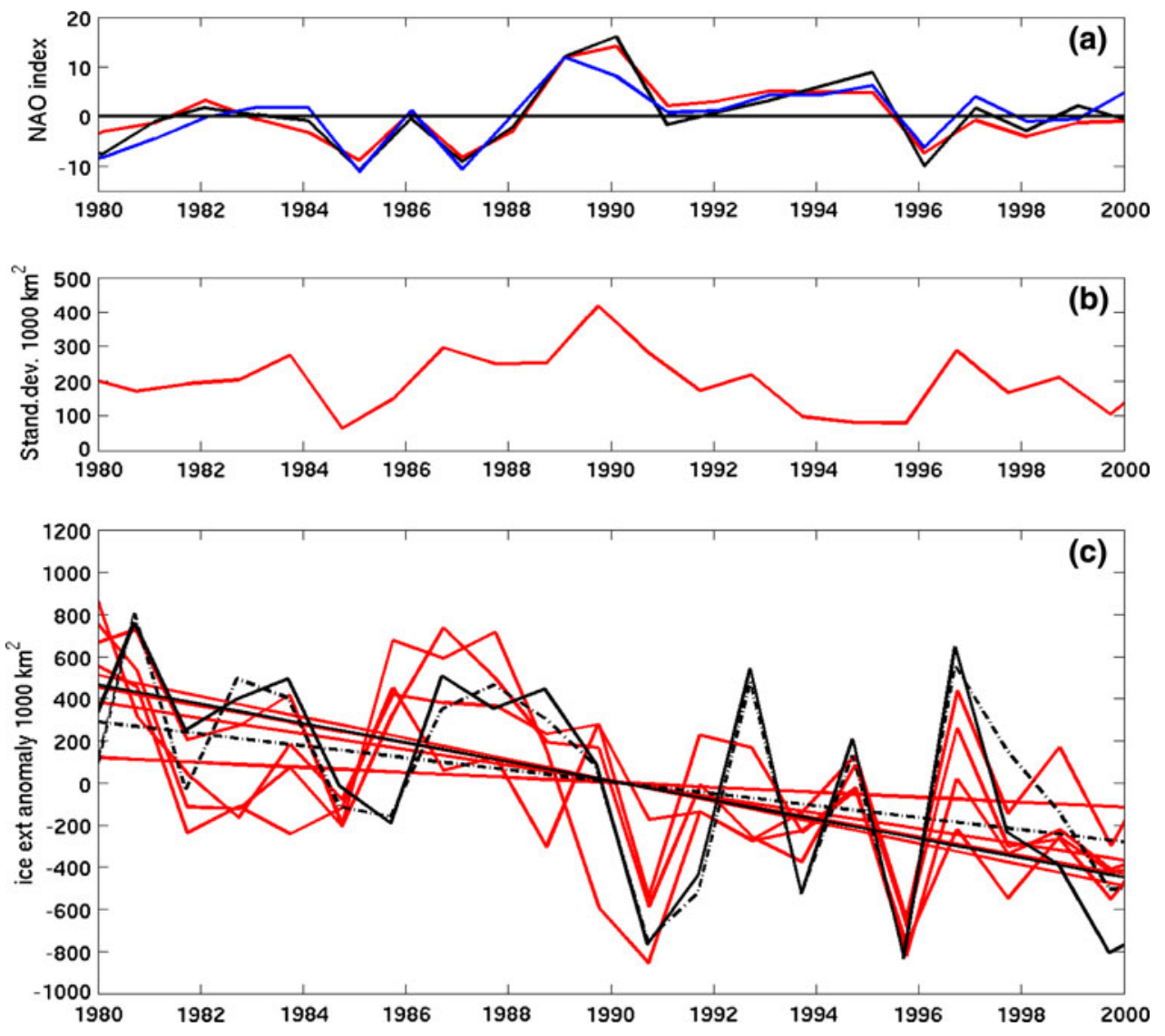

From observations, there is indication for a connection between summer sea ice extent and the atmospheric winter surface circulation over the North Atlantic and the Arctic, as monitored by the North Atlantic Oscillation (NAO) index during certain phases. Long term positive NAO conditions are associated with anomalously cyclonic atmospheric circulation over wide Arctic areas, which forces the sea ice away from the Eurasian and Alaska coasts (Rigor et al. 2002; Serreze et al. 2007), and leads to reduced ice concentrations in the outflow regions ( $\mathrm{Hu}$ et al. 2002). Holland (2003) concurs with that picture, based on the behavior of the global coupled Community Climate System Model CCSM2. Testing such a relation for our RCAO ensemble, we define a NAO index here as the atmospheric winter surface pressure difference between the Azores region (outside the RCAO model domain), taken from the ERA-40 data, and the Iceland area from inside RCAO's model domain (Fig. 3a). This simulated NAO index closely follows the observed one. We find that high $\mathrm{NAO}$ index phases $(\mathrm{NAO}+)$ are generally associated with low summer sea ice extent (Fig. 4) for the period 19802000. The correlation coefficients are -0.58 for RCAO and -0.46 for ERA-40. Sea level pressure (SLP) and overall sea ice extent in the ERA-40 reanalysis are considered especially reliable. Our correlations would likely be less if

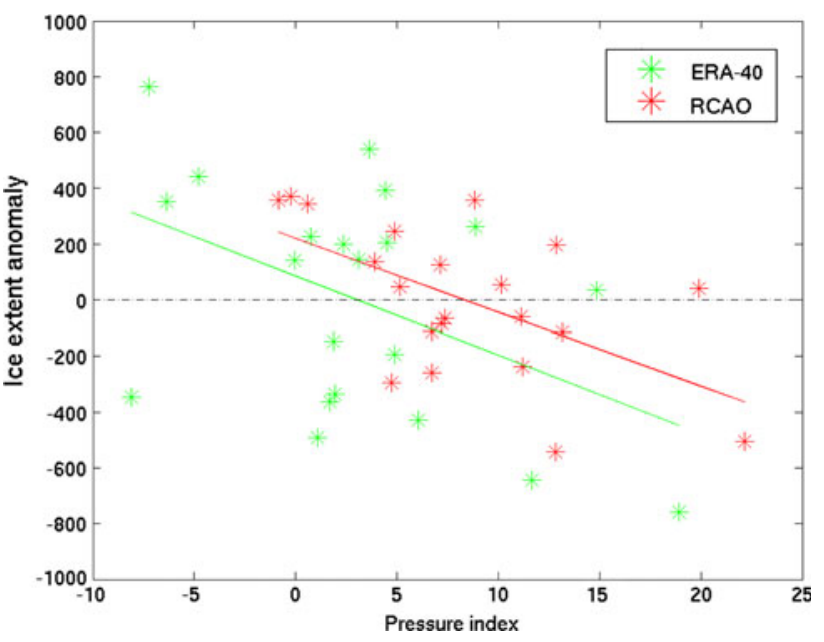

Fig. 4 Summer sea ice extent anomaly versus winter NAO pressure index, based on September mean ice extents and January-March winter NAO index mean of the years 1980-2000

calculated for the longer time span 1960-2000, because the NAO pattern was shifting around 1980 and was less efficiently impacting on Arctic sea ice export before (Hilmer and Jung 2000). Other observational and model-based studies often show similar relations, but correlation coefficients cannot be compared directly due to methodical 
differences. Holland (2003) calculates a correlation between the leading mode of summer sea ice variability and a simulated winter NAO-AO index of only 0.14 , based on CCSM2 results. The low value is likely due to discrepancies between simulated and observed ice movement. A more detailed regression analysis by Holland (2003) indicates that ice variability in the Siberian sector is consistent with NAO index variability, but is not purely NAO or AO forced. Similar findings are presented in observational study of Rigor et al. (2002) and Hu et al. (2002).

A map of the sea ice cover of the ensemble mean and the ERA-40 reanalysis is given in Fig. 5. A general agreement can be seen for high ice concentration in the central Arctic Ocean and a zone of reduced concentrations during summer (JAS) in the vicinity of the margins. There are deviations in the location of the ice margin. During summer, the coupled model gives generally too little ice cover in the Kara Sea and too much coastal ice cover in the Bering and Eastern Siberian sector. That is a typical feature of a sea ice model with a single sea ice class such as the current version of RCO (see e.g. Vancoppenolle et al. 2008). During winter time (JFM), the coupled simulations give somewhat too little ice coverage between the islands of Spitsbergen and Novaya Zemlya. The simulated ice branch along the east coast of Greenland is thinner than observed, though the "Is-Odden" feature, an eastward hook-like sea ice extension attributed to interaction of Greenland Sea ocean circulation and local upwelling, is clearly visible in the simulations.

Sea ice concentration trends over the 1980s and 1990s are presented in Fig. 6. Again the general patterns for summer and winter seasons are well comparable with the ERA-40 data set. In accordance with the sea ice concentration field (Fig. 5), a lower than observed concentration trend is seen in the East Siberian sea. However, the very same area shows the strongest thinning trend (Fig. 7), but a signal in the ice concentration is prevented by too thick ice. Observed patterns of thickness trend as a reference for model development are not available on the Arctic large scale. Only spatially and temporally limited trends exist which cannot be used here. Instead, a comparison with the well validated ocean-ice-standalone model of the Applied Physics Laboratory APL/University of Washington (Rothrock et al. 2003) shows a very similar trend pattern with a maximum off the eastern Siberian coast and an elongated tongue along the trans-Arctic drift towards Fram Strait. The ensemble mean sea ice seasonal concentration trends as presented here are generally not statistically significant, based on the results of a $t$ test. This is true for both the model ensemble and the ERA-40 data set. The reason is found in a strong interannual variability at the ice edge. Note that this is not affecting the significance in the overall Arctic sea ice extent. Contrary to the concentration trends, the ensemble mean thickness trends are significant in wide
Fig. 5 Mean sea ice concentration summer (JAS, left panel), winter (JFM, right panel) for RCAO (upper panel) and ERA-40 (lower panel) for the period 1980-2000
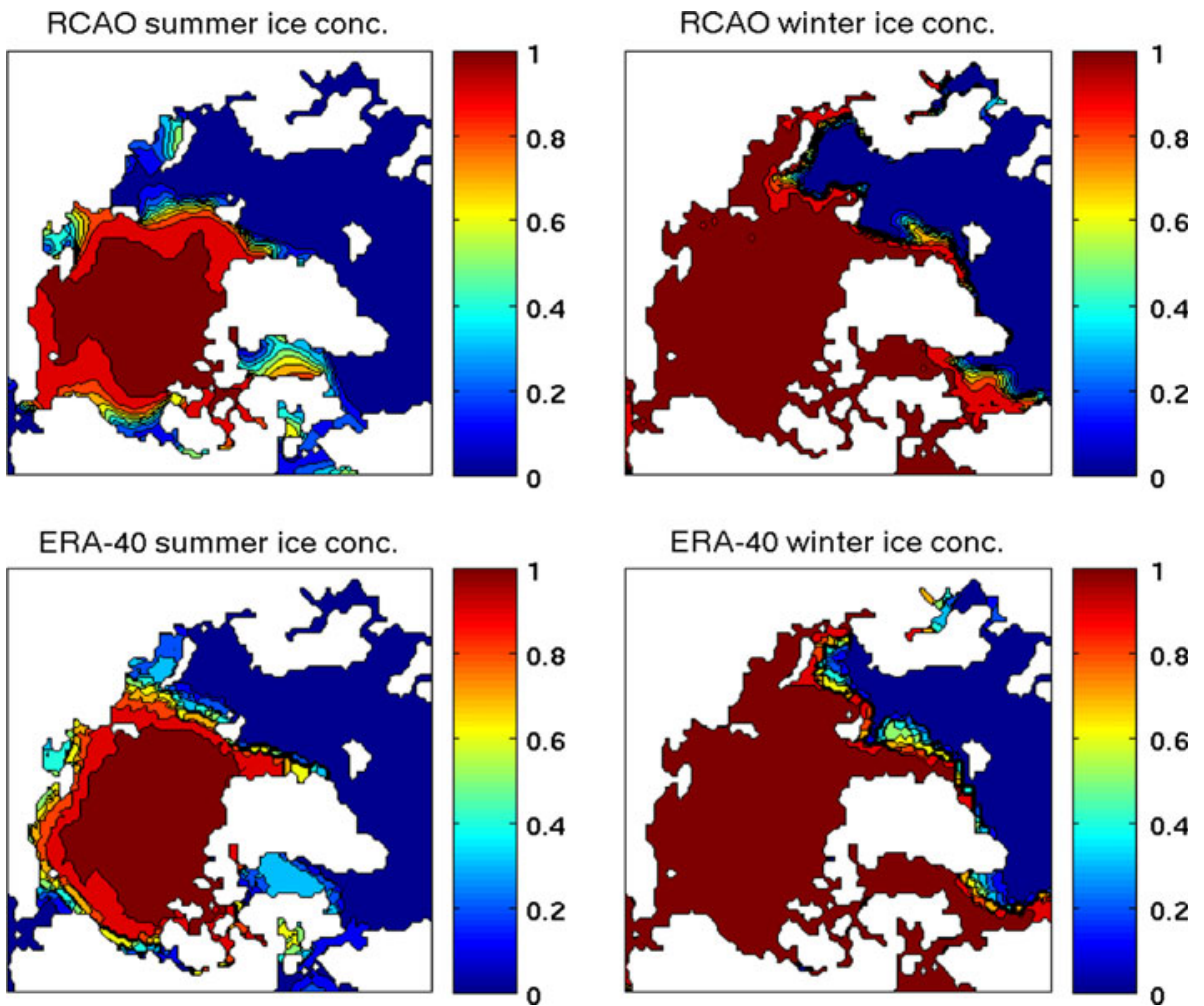
Fig. 6 Sea ice concentration trend 1980-2000, summer (left) and winter (right) for RCAO (upper panel) and ERA-40 (lower panel). Values in concentration change per year (1/year)
Fig. 7 Ensemble mean sea ice thickness trends for summer (left) and winter (right) in $\mathrm{cm} /$ year. The time period covered is 1980-2000. Red overlay contours indicate statistical significance levels of 1,3 and $5 \%$ from the interior to the outside
RCAO summer $1980-2000$

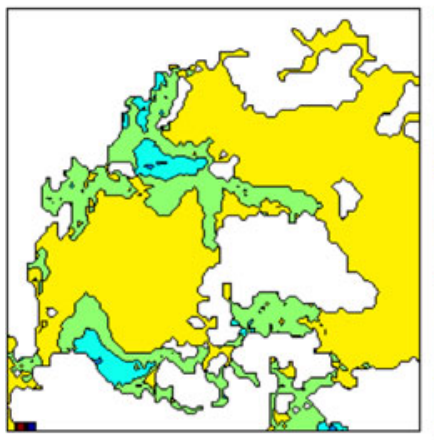

ERA summer $1980-2000$

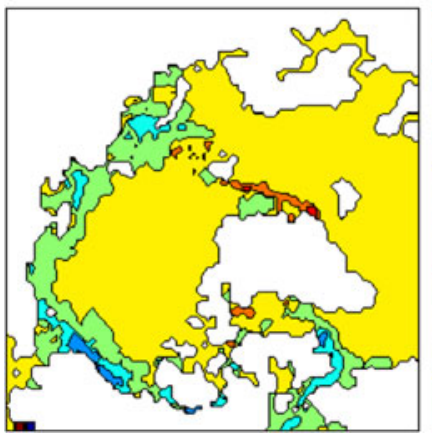

0.04

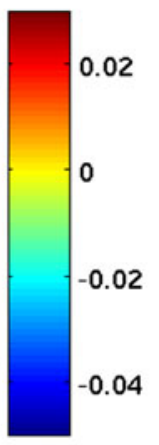

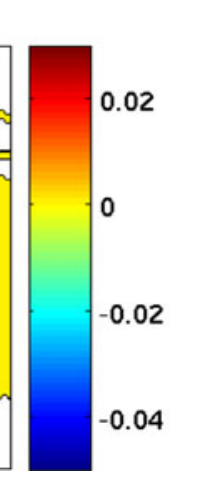

\section{Summer thickness trend}
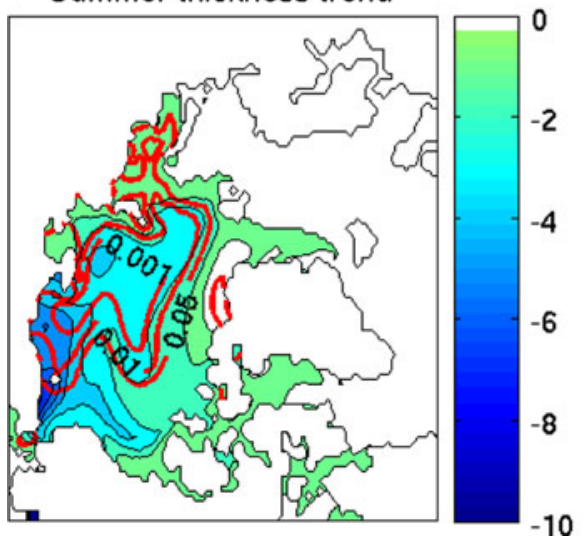

RCAO winter $1980-2000$

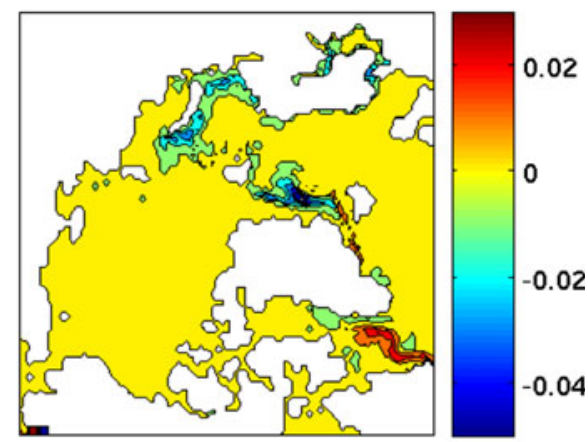

ERA winter $1980-2000$

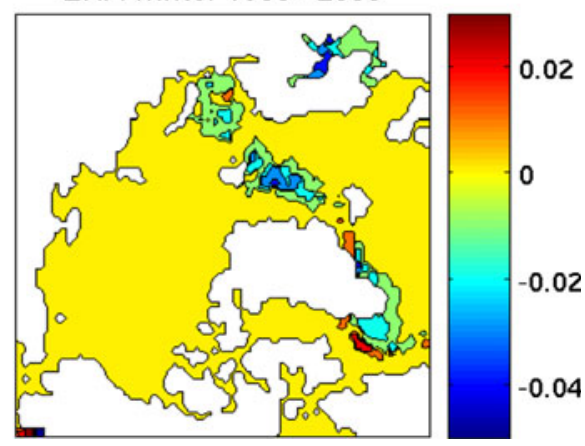

$-0.04$

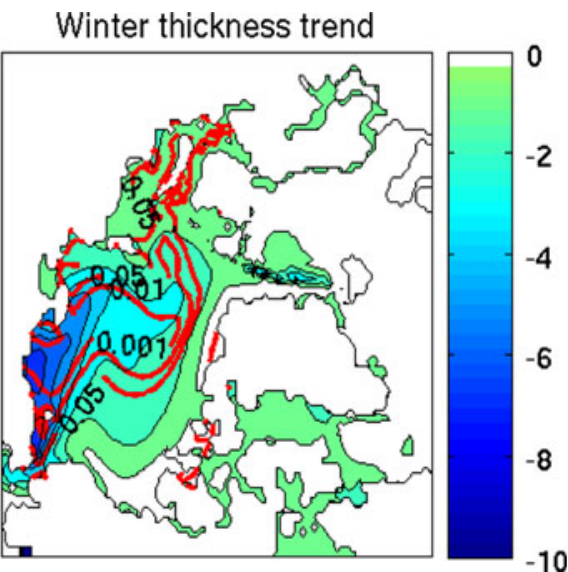

areas. The overlay contours in Fig. 7 give the 1, 3 and 5\% significance levels based on a simple $t$ test comparing the means of the years 1980-1989 with 1990-2000. In the next section we are able to relate the significant thickness trend to external forcing.

\section{Ensemble spread, variability and predictability}

In this work we estimate the relative importance of internally generated variability versus externally forced variability. Despite almost identical initial conditions, the ensemble members show substantial differences during certain periods. As the outside forcing is identical for all runs, differences must be due to internal Arctic processes.

We start to describe intra-ensemble differences by selected illustrative examples (differences in decomposition into empirical orthogonal functions (EOFs), correlations between sea ice thickness and NAO, and the intra-ensemble standard deviation with its relation to the NAO) before we explore the ratio of external and internal variability based on the concept of prognostic potential predictability (PPP) (Pohlmann et al. 2004). A measure of the variability generated inside the Arctic is given by the spread between the ensemble members. The standard deviation for the summer sea ice extent within the 
ensemble is given in Fig. 3b. It gives us a glimpse on the possible role of internal variability within the coupled Arctic atmosphere-sea ice-ocean system.

A first approach to quantify intra-ensemble differences is an EOF analysis of each ensemble member. We apply that method to the SLP fields, which represent a major driving force for the sea ice. The analysis is carried out individually for each ensemble member and is thereafter averaged over the ensemble. The 1st EOF calculated within the RCO model domain (Fig. 8) is reminiscent of the Arctic oscillation (AO) pattern in this area (Zhou et al. 2001) with positive amplitudes covering most of the Arctic ocean and the Nordic Seas. During winter, the explained variance is between 43 and $56 \%$ for individual ensemble members. The 2nd EOF displays an oscillation between the Arctic ocean and the Nordic Seas and explains variance between 16 and $22 \%$. This oscillation is often referred to as dipole anomaly (DA) (Wu et al. 2006). The 3rd EOF gives a tri-pole pattern between the central Arctic ocean and the North-Eastern North Atlantic on the one hand side and over the Norwegian and Barents Sea on the other hand side. The explained variance during winter is found between 12 and $15 \%$.
All EOFs vary in shape between the four ensemble members P1-P4. In order to get a quantitative measure of the ensemble spread, we calculate the standard deviations within the four EOFs of each order. Before that, each EOF is multiplied by the square root of the variance of the respective principal component time series in order to allow for comparability between the EOFs $1-3$. The standard deviations within the four EOFs (one for each ensemble member) of each order show little difference between the orders $(0.45 \mathrm{hPa}$ for the 1 st order, $0.52 \mathrm{hPa}$ for the $2 \mathrm{nd}$ order, $0.54 \mathrm{hPa}$ for the $3 \mathrm{rd}$ order in spatial mean during winter). Thus, all three EOFs contribute similarly to intra-ensemble differences in wind driving of ocean and sea ice, with the 2nd and 3rd EOF contributing somewhat more that the 1 st EOF during winter.

Further differences between the ensemble runs P1-P4 are found for the relation between NAO and sea ice thickness. It is well established from other studies (e.g. Polyakov et al. 2003) that a positive NAO index is connected with warmer surface air temperature and less ice in the Barents and Kara Sea. This leads to a reduced Arctic ice cover (Serreze et al. 2007). Our model runs give similar
Fig. 8 EOF $1-3$ of the winter (JFM, 1st row) and summer (JAS, 3rd row) sea level pressure (SLP) fields as ensemble mean, and intraensemble standard deviation (2nd and 4th row), illustrating the ensemble spread of each EOF. Numbers for explained variance in $\%$ and mean values for standard deviations are given on top of the frames. Note that the color bars for the standard deviations differ for summer and winter
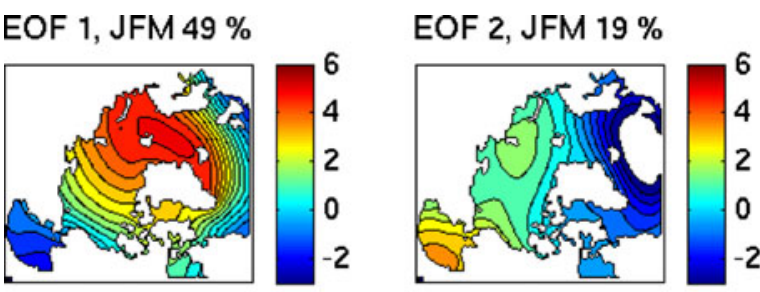

Std 1, 0.45

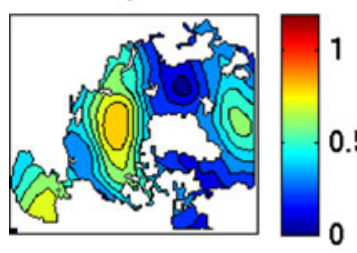

EOF 1, JAS $38 \%$

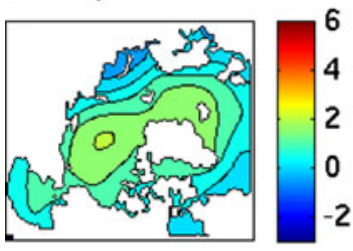

Std 1, 0.49

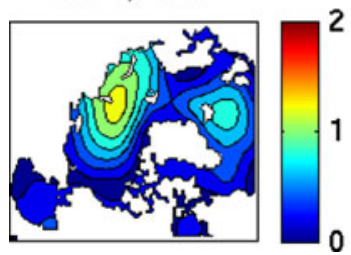

Std 2, 0.52

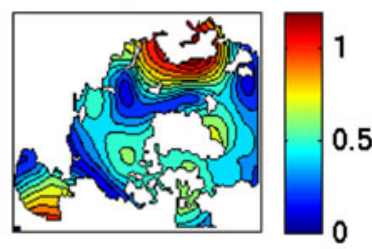

EOF 2, JAS $23 \%$

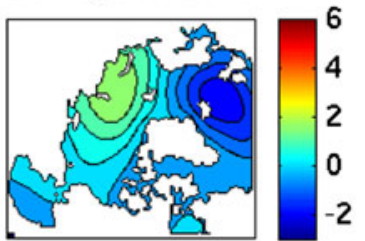

Std 2, 0.45

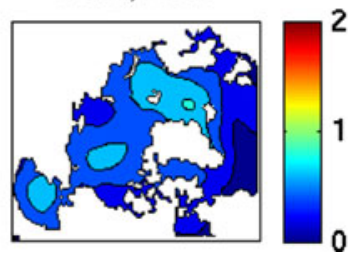

EOF 3, JFM $14 \%$

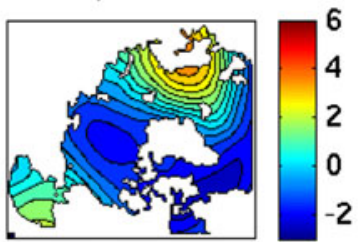

Std 3, 0.54

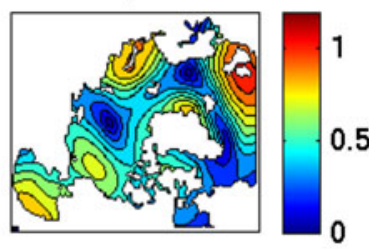

EOF 3, JAS $12 \%$

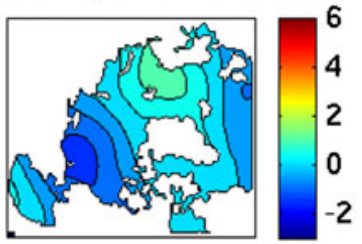

Std 3, 0.36

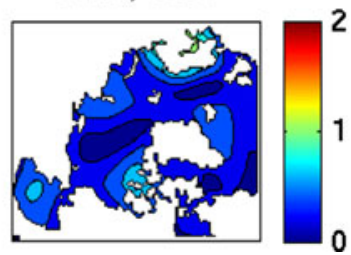


results as documented for the ice extent in the previous section. Here we show the correlation between our winter (JFM) NAO index and the simulated ice thickness during summer (Fig. 9). A positive NAO is clearly connected with thinner ice in the wider area between Fram Straits and the Kara Sea, and along large parts of the Siberian coast. Furthermore, the positive NAO is connected with thicker ice in specific regions in the central Arctic and off the Canada-Alaska coastal region. Maximum correlations around 0.6 are found. The specific shape of the NAO correlation with the ice thickness varies between the runs $\mathrm{P} 1-\mathrm{P} 4$, but the general pattern exists in all ensemble members.

A distinct agreement between all simulations and observations of summer sea ice extent anomaly is seen during the year 1995 (Fig. 3c) which shows a strong minimum. Starting 1990, almost each consecutive year shows a reduced standard deviation (Fig. 3b) and thus shows a better agreement between the ensemble members. This temporary trend in the intra-ensemble standard deviation coincides with a longer period of positive NAO index years (Fig. 3a). This indicates a control of Arctic internal variability by long term large scale circulation trends, especially under the specific atmospheric large scale circulation situation of a positive NAO.
An additional reason for the close agreement of all ensemble members in 1995, possibly related to the positive NAO phase, is seen in a strong sea ice flushing event visible in most of the simulations during that year (no figure). Such strong events leave little room for effects of internal non-linear processes. Increased sea ice export after the late 1970s (Hilmer and Jung 2000) is often attributed to positive NAO situations (Hu et al. 2002).

This multiyear trend in the intra-ensemble standard deviation during the period 1990-1995 is unique in our analysis period. Outside this period, no such relation between the intra-ensemble spread and the NAO index can be found. Therefore, we search for other SLP patterns associated with the intra-ensemble spread. We correlate the time series of summer mean SLP fields with the intraensemble standard deviation (the spread) of sea ice extent (as shown in Fig. 3b). The correlation pattern for the ensemble (Fig. 10) shows negative correlations over the Labrador Sea and in the Nordic Seas, extending into the Arctic Ocean north of Greenland, and positive correlations mostly over the Kara Sea. The correlation pattern in Fig. 10 has been generated by extending the spread curve with itself four times, and by concatenating spring-summer (MJJAS) mean fields of SLP of the four ensemble runs. Even all
Fig. 9 Correlation between simulated winter (JFM) NAO index and summer ice thickness fields for the years 1980-2000. Calculations are based on the predictability runs $\mathrm{P} 1-\mathrm{P} 4$
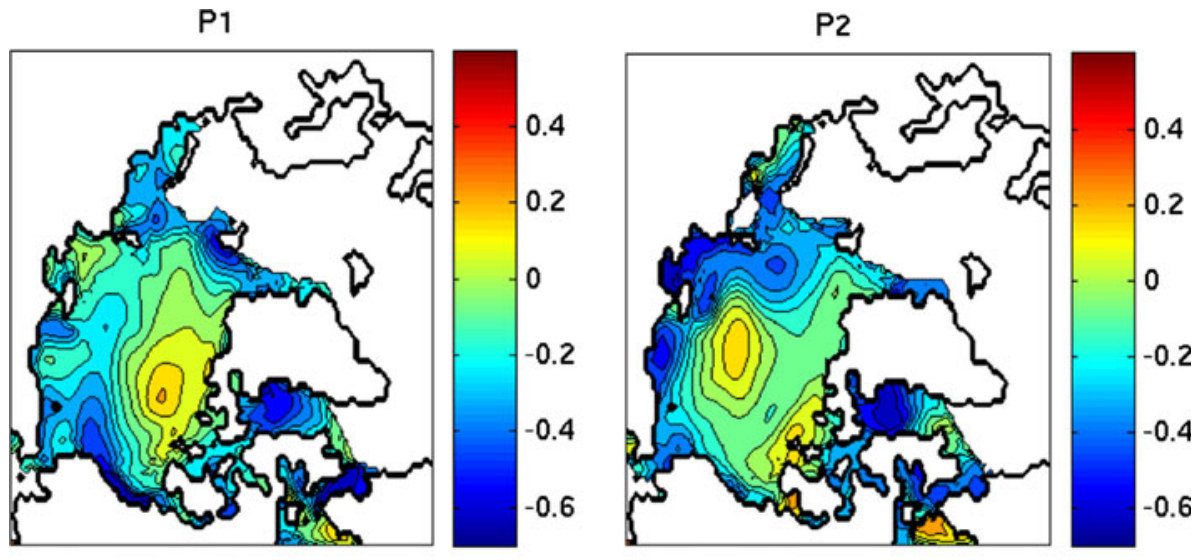

P3
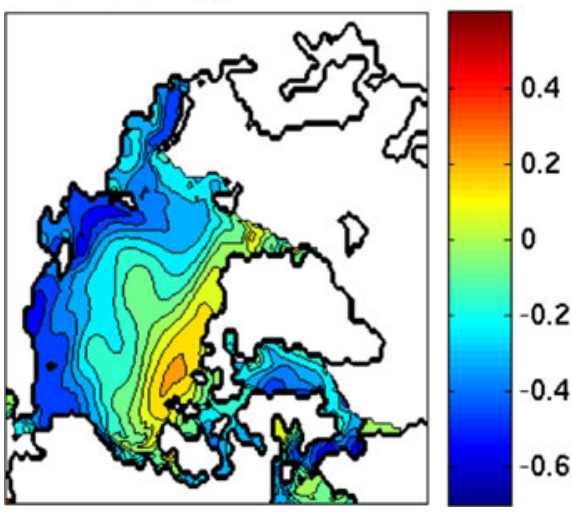

P4

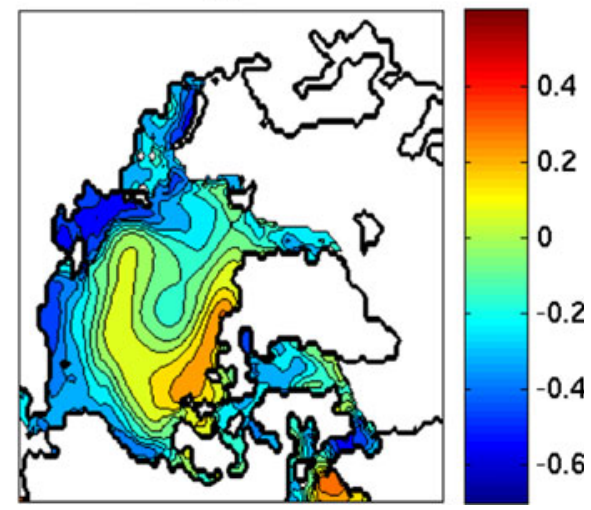




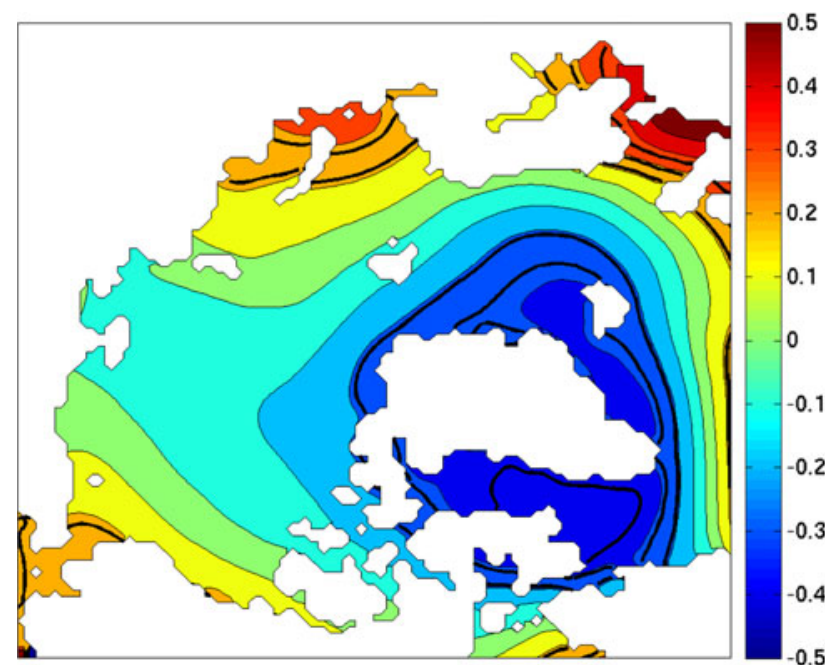

Fig. 10 Correlation between intra-ensemble spread of sea ice extent (Fig. 3b) and sea level pressure (SLP) during spring-summer (MJJAS). Black contours indicate statistical significance on the 5\% and better levels

individual ensemble members (no figure) show a correlation gradient between the Nordic Seas and the Kara Sea.

The pressure pattern associated with the correlation pattern implies a wind anomaly from northern Scandinavia across the Barents Sea towards Northern Greenland. This wind anomaly shows similarities to those associated with the 2nd EOF of SLP (Fig. 8). Both during summer and winter the wind link between Northern Scandinavia and Northern Greenland is present as a SLP gradient between the Nordic Seas and the Arctic Ocean (Fig. 8) with explained variances between 19 and 23\%. We conclude that the intra-ensemble spread in sea ice extent can be partially associated with a surface pressure gradient between the Nordic Seas and the Kara Sea/Laptev Sea. Strong south-easterly wind anomalies from Scandinavia are connected with high intra-ensemble spread and vice versa. Northerly wind anomalies support ice export and favor low intra-ensemble spread. Our finding is supported by a similar 2nd order EOF of SLP in global models found by Wu et al. (2006) and described as DA. That DA pattern is associated with a strong influence on sea ice export.

After the above examples of intra-ensemble differences and their nature, we are now looking for a method to give us a measure of the system's predictability, i.e. the potential for a coupled prediction. The more a system is determined by the externally forced variability and the smaller the intra-ensemble spread is, the better are the possibilities for a prediction, provided the external forcing is known or it originates from large scale long-term prediction effort with a skill.

The internally generated variability of a model variable in the Arctic system ("internal variability") at any grid point is assessed by the time average of the standard deviations within the ensemble (the mean internal variability MIV):

$\mathrm{MIV}=\frac{1}{N} \sum_{t=1}^{N}\left(\frac{1}{M} \sum_{m=1}^{M}\left(x_{m, t}-\bar{x}_{t}\right)^{2}\right)^{1 / 2}$

with $x_{m, t}$ a climate variable of a given ensemble member at a time $t, x_{t}$ the ensemble average at a time $t, M$ the number of ensemble members $(M=4$ in our case), and $N$ the length of the time series. The calculation is based on seasonal mean averages varying over 21 years (1980-2000) of the ERA-40 covered period. The MIV gives a measure of system "noise" which is inherently unpredictable on long time scales, although its amplitude can potentially be reduced under certain large scale circulation conditions, i.e. by positive NAO situations or by a surface pressure gradient from Nordic Seas to the Kara Sea as described above. It is unclear at this point to what extent the internal variability can be reduced or possibly increased by improved model parameterizations.

The externally driven part of the variability of a model variable in the Arctic system ("external variability") originates from the lateral forcing at the outer boundaries of the coupled model and from the top-of-atmosphere forcing. A similar behavior of the different ensemble members is interpreted as driven by the outside forcing with only little influence of internal processes. The external variability (EV) at any grid point can be assessed by the standard deviation of the ensemble mean time series.

$\mathrm{EV}=\left(\frac{1}{N} \sum_{t=1}^{N}\left(x_{E, t}-\bar{x}_{E}\right)^{2}\right)^{1 / 2}$

Our calculations are again based on seasonal mean fields varying over 21 years during the period 1980-2000.

The definitions for internal and external variability correspond to the formalism of prognostic potential predictability (PPP) introduced by Phelps et al. (2004) and Pohlmann et al. (2004) for a global scale analysis and discussed by Knopf (2006). Pohlmann et al. (2004) estimate the external variance based on a longer reference simulation, which is not available in our case. Instead we choose the ensemble average time series at each grid point as a reference, similar to the approach of Mikolajewicz et al. (2005) using a 'common variability'. This must lead to an underestimation of the external signal, however the results are not qualitatively affected (no figure).

Analyses of the internal and external parts of the Arctic variability according to 2) and 2) are applied to sea ice thickness during summer (Fig. 11) and winter (Fig. 12). Both internal (left picture in Figs. 11 and 12) and external variability (center picture in Figs. 11, 12) of ice thickness 
are strongest at the coasts with maximum values in the Siberian sector and smaller values off the northern Greenland coast. The central Arctic Ocean shows a small signal indicating little interannual variability. The relative importance of external and internal variability is estimated by the signal/noise $(\mathrm{S} / \mathrm{N})$ ratio (Figs. 11, 12c),

$S / N=\frac{\mathrm{EV}}{\mathrm{MIV}}$

with the signal being the external variability and the noise being represented by the internal variability not controlled by any forcing. $S / N$ values larger than 1 in Figs. 11 and 12 indicate a stronger influence of external forcing versus internally generated non-linear chaotic variability. For the most part the external signal is larger by factors between 1 and 2. Dominating external variability is supportive to prediction because the Arctic variability can be inferred from large scale fields. Strong internal variability adds to the uncertainty of a prediction. Therefore, the $S / N$ ratio is a measure of the potential of a prediction system, i.e. the predictability.

When using the formalism above, we are interested in distinguishing horizontal areas with mostly externally driven variability from areas with internally dominated variability. To prove that difference, we test the significance of $S / N$ ratios greater than unity (one), which indicate a certain degree of predictability. Ratios smaller than one indicate only a small influence of external processes and thus low potential predictability. To consider $S / N$ ratios to be significantly controlled by external forcing, we require the values to exceed the square root of the $90 \%$ percentile of the F-distribution (compare with Neter et al. (1988) for a derivation of significance for ANOVA (analysis of variance) experiments). Differences to a similar criterion of Pohlmann et al. (2004) are due to the different definition of the signal/noise ratio used here. In our configuration this translates to a $S / N$ value of at least 1.37. Most of our $S / N$ illustrations (Figs. 11, 12, 13, 14, 16, 17) show areas exceeding that value, which allows us to distinguish between externally forced areas on the one hand side and areas with a non-significant signal/noise ratio on the other hand side. The latter indicates an important role for internally generated variability, which is supported by $S / N$ ratios smaller than unity (one) in certain regions.

During summer (Fig. 11), the strongest signals in sea ice thickness are seen in the eastern Siberian, Alaska and Canada sectors with an additional maximum north of the Kara Sea. $S / N$ ratios smaller than 1, i.e. ratios connected to small external interannual variability are dominating in the Kara Sea, at the ice margins and north and east of Greenland, indicating importance of internal local coupled processes at the ice margin and in the Fram Strait area. The strong externally forced areas $(S / N>1)$ fit widely with the pattern of negative correlation between NAO winter index and simulated sea ice thickness fields (Fig. 9). This suggests an influence to the NAO large scale forcing on $S / N$ fields and thus on the predictability of the system, which is more permanent within our time period of consideration 1980-2000, compared to the NAO's influence on the overall Arctic Sea ice extent.

During winter (Fig. 12), the external forcing is dominating the interannual ice thickness variability in most areas,
Fig. 11 Internal (left), external (center) variability of Arctic summer (JAS) sea ice thickness for the period 1980-2000 in cm, and signal/noise ratio (external/ internal) (right)

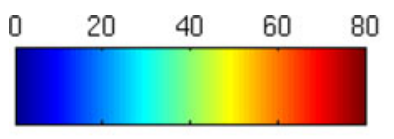

internal $1980 \cdot 2000$

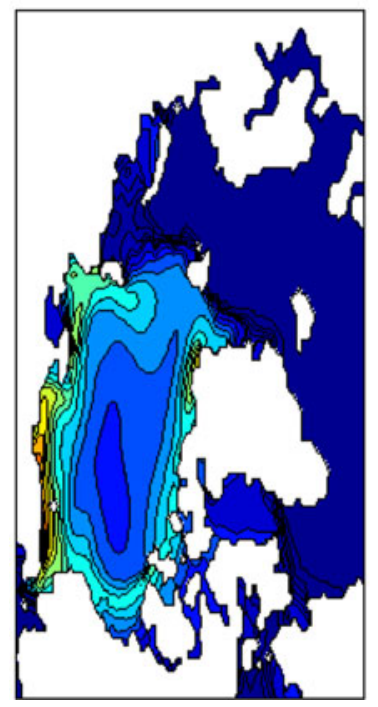

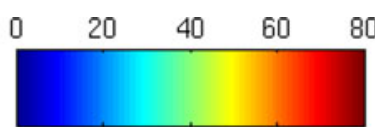

external $1980-2000$

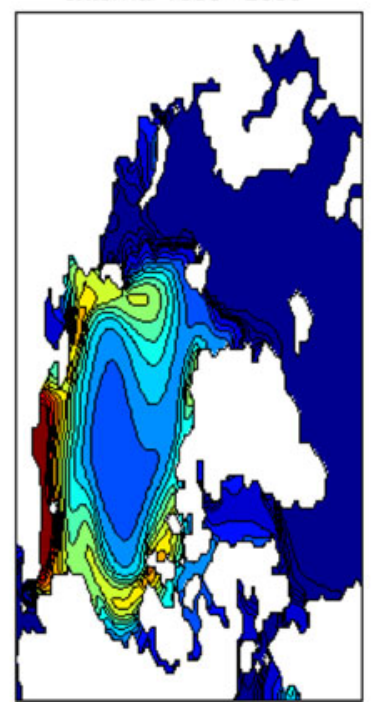

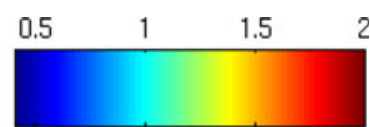

signal/noise $1980-2000$

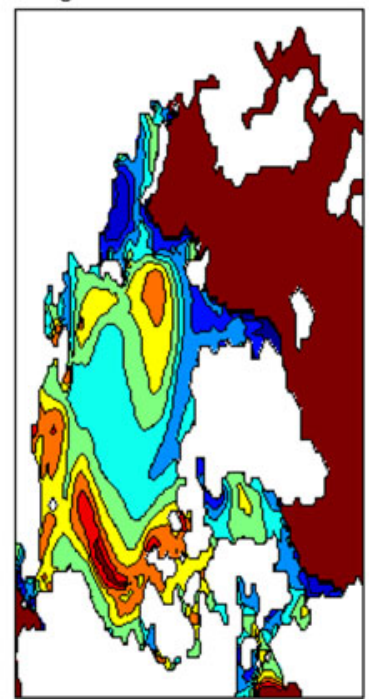


Fig. 12 Internal (left), external (center) variability of Arctic winter (JFM) sea ice thickness for the period 1980-2000 in cm, and signal/noise ratio (external/ internal) (right)
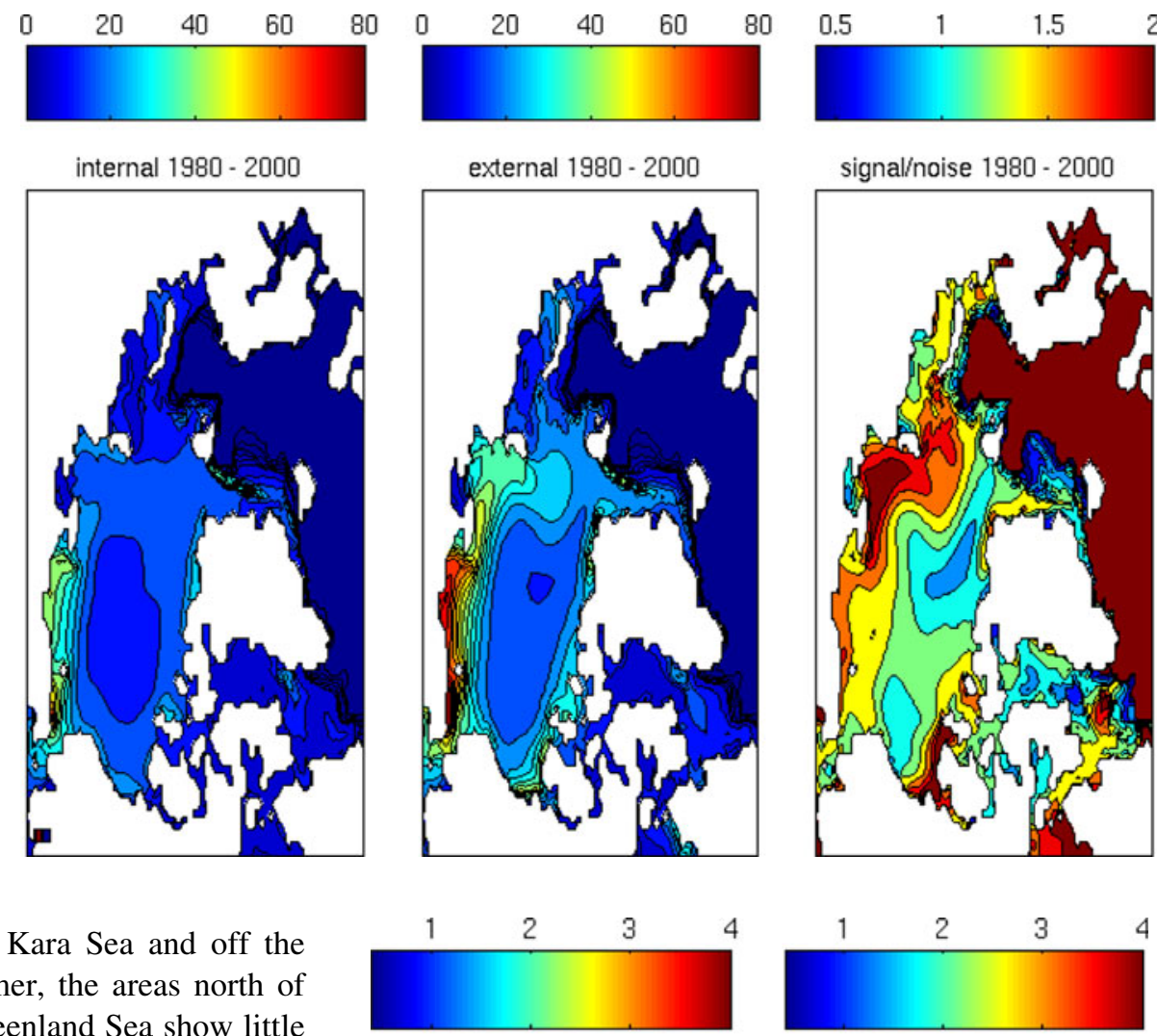

with the strongest $S / N$ ratio in the Kara Sea and off the western Siberian coast. As in summer, the areas north of Greenland and large parts of the Greenland Sea show little external variability and are dominated by internal processes.

The above calculations of the $S / N$ ratio are carried out based on trend-afflicted time series of sea ice thickness. The $S / N$ ratios for the de-trended thickness time series are very much similar to the original trend-afflicted, in shape and amplitude (no figure). Thus, all the statements above on the original $S / N$ hold even for the de-trended case. The trend does not affect the distribution of internally generated and externally forced interannual variability. In Fig. 13 we present the $S / N$ ratios for the summer and winter trend. The $S / N$ ratios for the trend look quite different compared to the trend-afflicted case: Areas of strong external control are coinciding with the areas of strongest trend signal and for the most part even with the high significance area of the trend (Fig. 7). This is true for both summer and winter. We conclude that large scale sea ice thickness trends are attributed with a high degree of significance to the physical conditions at the lateral boundaries of our regional model domain.

For the 2-m air temperature (T2M) over the ocean during winter, the external part of the variability (Fig. 14) is clearly stronger than the internal part in areas away from a band along the northern and eastern Greenland coast and the Greenland Sea. T2M over sea ice is determined by the ocean/ice surface temperature, which during winter depends very much on the ice thickness and on the large scale atmospheric circulation over the ice. This is explaining the strong dominance of external forcing (representing similar behavior of ensemble members) and the

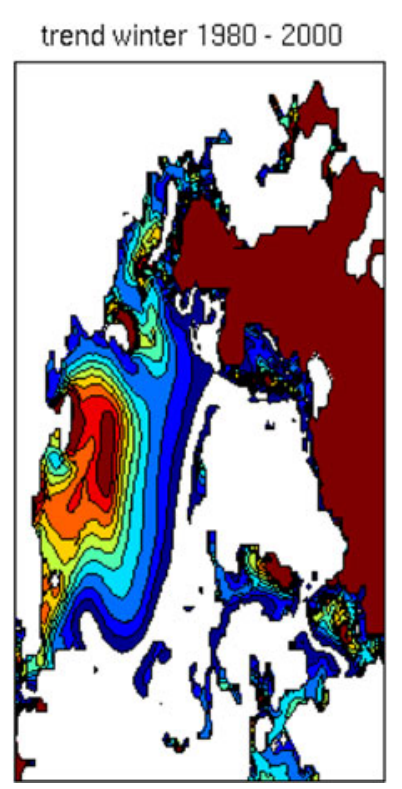

trend summer $1980-2000$

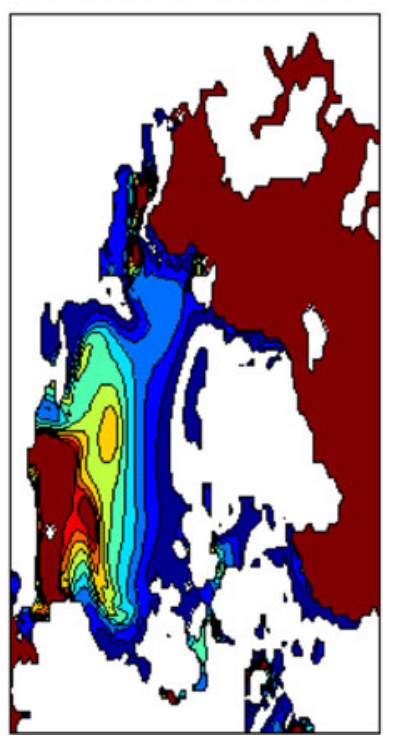

Fig. 13 Signal/noise ratios for sea ice thickness during winter (left) and summer (right), based on the trend between 1980 and 2000. Contour levels are limited to ensure comparability

similarity between $S / N$ rations for T2M (Fig. 14) and ice thickness (Fig. 12) during winter. The general pattern of T2M total variability (internal + external variability, dominated by the external variability in this case) is confirmed by the ERA-40 T2M variability (not shown here). 
Fig. 14 Internal (left), external (center) variability of Arctic winter (JFM) 2-m-air temperature for the period 1980-2000 in K, and signal/ noise ration (external/internal) (right)
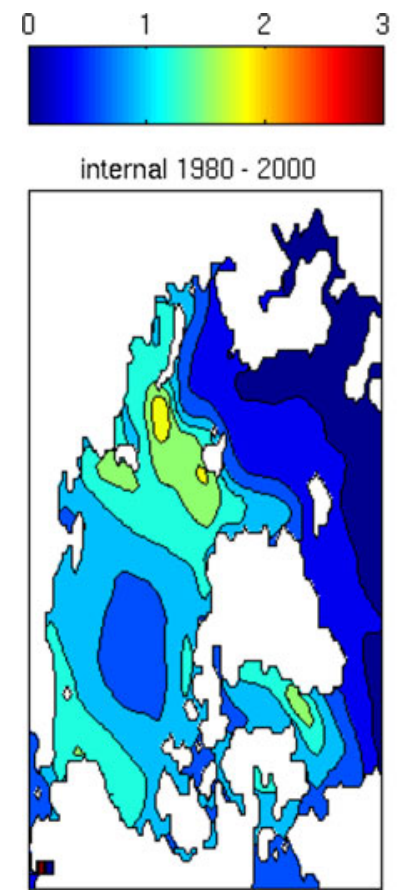

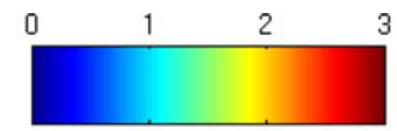

external $1980 \cdot 2000$

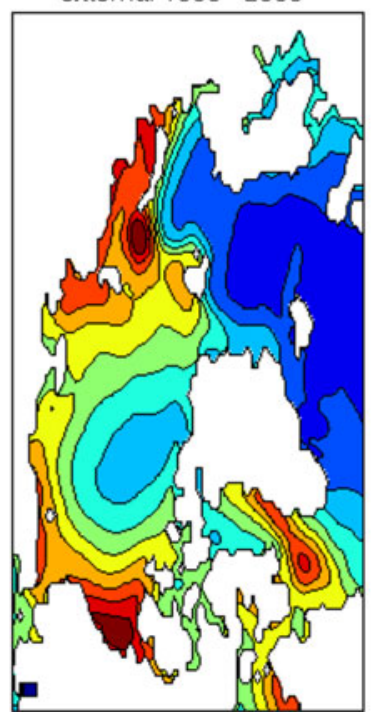

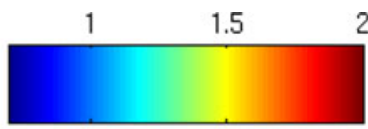

signal/noise $1980 \cdot 2000$

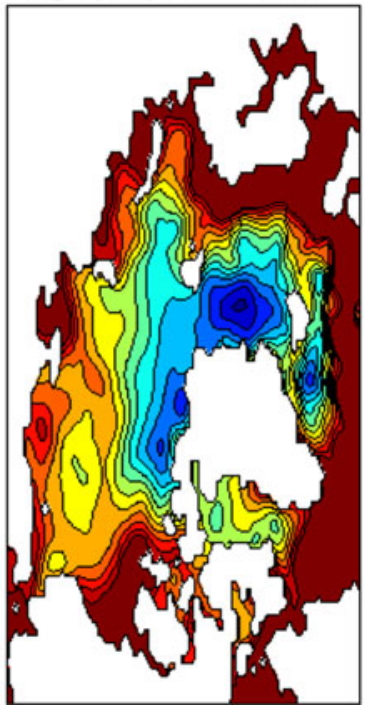

Summer total variability is much smaller than winter total variability in both ERA-40 and in our ensemble. This is due to ice surface temperature rising to the freezing point during summer. That process is less subject to large scale dynamics. It is interesting to note that internal processes are important in a wide area centered around Fram Strait with high ice compression (north of Greenland) and ice export, influencing the Arctic overall ice extent.

Another way of assessing the relative importance of externally driven variability versus internally generated variability is the mean locking time fraction defined according to Knopf (2006). The state of "locking" at a time $\mathrm{t}$ is given when the spread within the ensemble is lower than a certain limit. More specifically, the spread expressed by the ratio of $L(t)$ Eq. (2) is required to be below a certain limit $\varepsilon$.

$L(t)=\frac{\left(\frac{1}{M} \sum_{m=1}^{M}\left(x_{m, t}-\bar{x}_{t}\right)^{2}\right)^{1 / 2}}{\mathrm{EV}}<\varepsilon$

In contrast to the $S / N$ definition above Eq. (2) no time averaging for the internal part is carried out. Here we chose $\varepsilon=1$. The mean locking time fraction (MLTF) is then given by the sum over all time intervals $t_{\text {lock }}$ under that limit, divided by the length of the time series ( $\mathrm{N}$ years, $N=21$ in our case):

MLTF $=\frac{100}{N} \sum_{n=1}^{N} t_{\text {lock }}$ with $t_{\text {lock }}= \begin{cases}0, & L(t) \geq \varepsilon \\ 1, & L(t)<\varepsilon\end{cases}$

The MLTF gives the percentage of time intervals with close ensemble members. Due to not averaging the internal part in time, this method gives clearer signals in case the simpler signal/noise method fails. We are utilizing this method in order to better identify reasons for the existence of internally dominated areas at the coasts north and east of Greenland.

Figure 16 shows the MLTF of wind direction for summer and winter. The winter pattern is clearly showing low locking time fractions in the rim north of Greenland and further through Fram Straits and into the Greenland Sea, indicating a strong role of internally generated wind direction variability. The horizontal pattern of winter wind direction locking (Fig. 15) is coinciding with the winter $S /$ $N$ ratio for T2M (Fig. 14) and thus suggesting a possible link. Summer locking is generally low over the Arctic Ocean, its coastal areas and over central Greenland.

Wind direction variability should be related to ice movement variability. Indeed, $S / N$ ratio patterns of sea ice velocity (Fig. 16) and sea ice velocity direction (not shown) both point to internally dominated or at least neutral conditions in most of the Arctic Ocean during summer and winter. For the ice velocity during winter (Fig. 16, right hand side), internal dominance is confined close to the Northern Greenland coast and parts of the Greenland Sea. V-like shapes for internally controlled area in the ice thickness variability (Figs. 11, 12) are similarly reproduced in the ice velocity variability (Fig. 16). We interpret these similarities as causal links between the variabilities of wind, ice movement and thickness.

Besides momentum fluxes (via wind), heat fluxes are the tool for communication between atmosphere, sea ice and ocean. How do the $S / N$ patterns discussed above translate 
into $S / N$ fields for heat fluxes? Considering the interannual variability of heat fluxes from atmosphere to ocean and atmosphere to sea ice, most components are dominated by

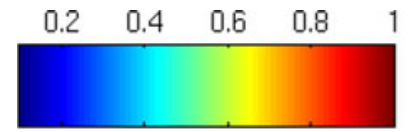

Locking, winter 1980 - 2000

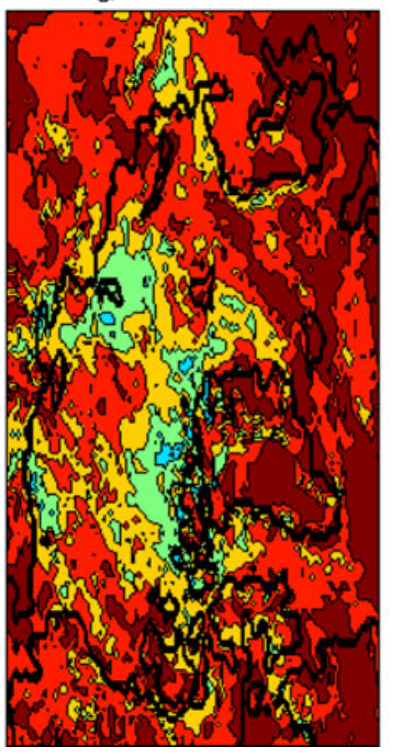

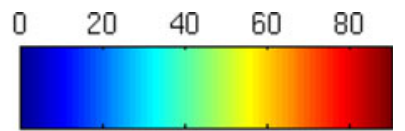

Locking, summer 1980 - 2000

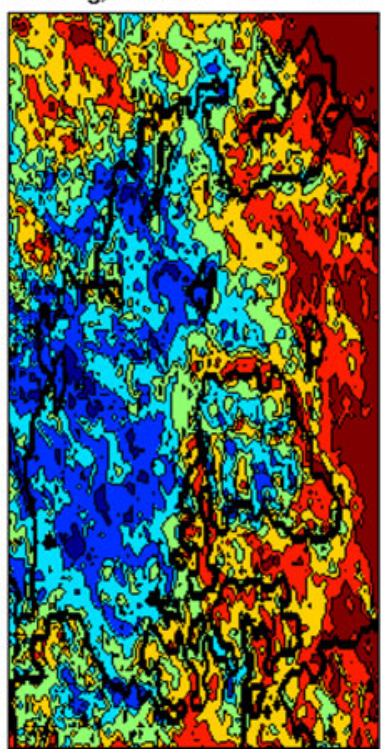

Fig. 15 Mean locking time fraction (MLTF) for 10-m wind direction in degrees for winter (left) and summer (right) internal variability in the Arctic (no figure). This is due to many direct influences on the local scale in addition to large scale circulation impact. Processes on the small scale affect cloud cover, cloud physics, surface temperatures etc. Among heat flux components such as longwave radiation, short wave net radiation and turbulent heat fluxes only the winter longwave downward radiation (LWD) shows a considerable structure in the signal/noise ratio for interannual variability (Fig. 17). Very much similar to the T2M signal/noise ratio (Fig. 14), external control is dominating along the coast of Norway, Russia and Alaska, while an area of neutral conditions (i.e. about equal importance of internal and external variability) is seen off the Canadian and Greenland coasts. This similarity between $\mathrm{T} 2 \mathrm{M}$ and LWD variability can be understood due to the strong cubic influence of air temperature on long wave downward radiation.

For several parameters (T2M, LWD, ice thickness and direction of wind and ice), we have now seen a dominance of internal interannual variability in an area covering a wider coastal strip north of Greenland and in parts of the Greenland Sea, in many cases (but not in all) close to the East Greenland coast. This is found mostly during winter. We hypothesize that the reason for this local dominance is interplay between the large scale circulation with the Greenland ice sheet's orography and katabatic winds arising from that cold surface orography. The large scale winds over the central Arctic Ocean are directed towards the
Fig. 16 Signal/noise ratio (external/internal) for sea ice velocity variability (upper panel) and $10 \mathrm{~m}$ wind velocity (lower panel)
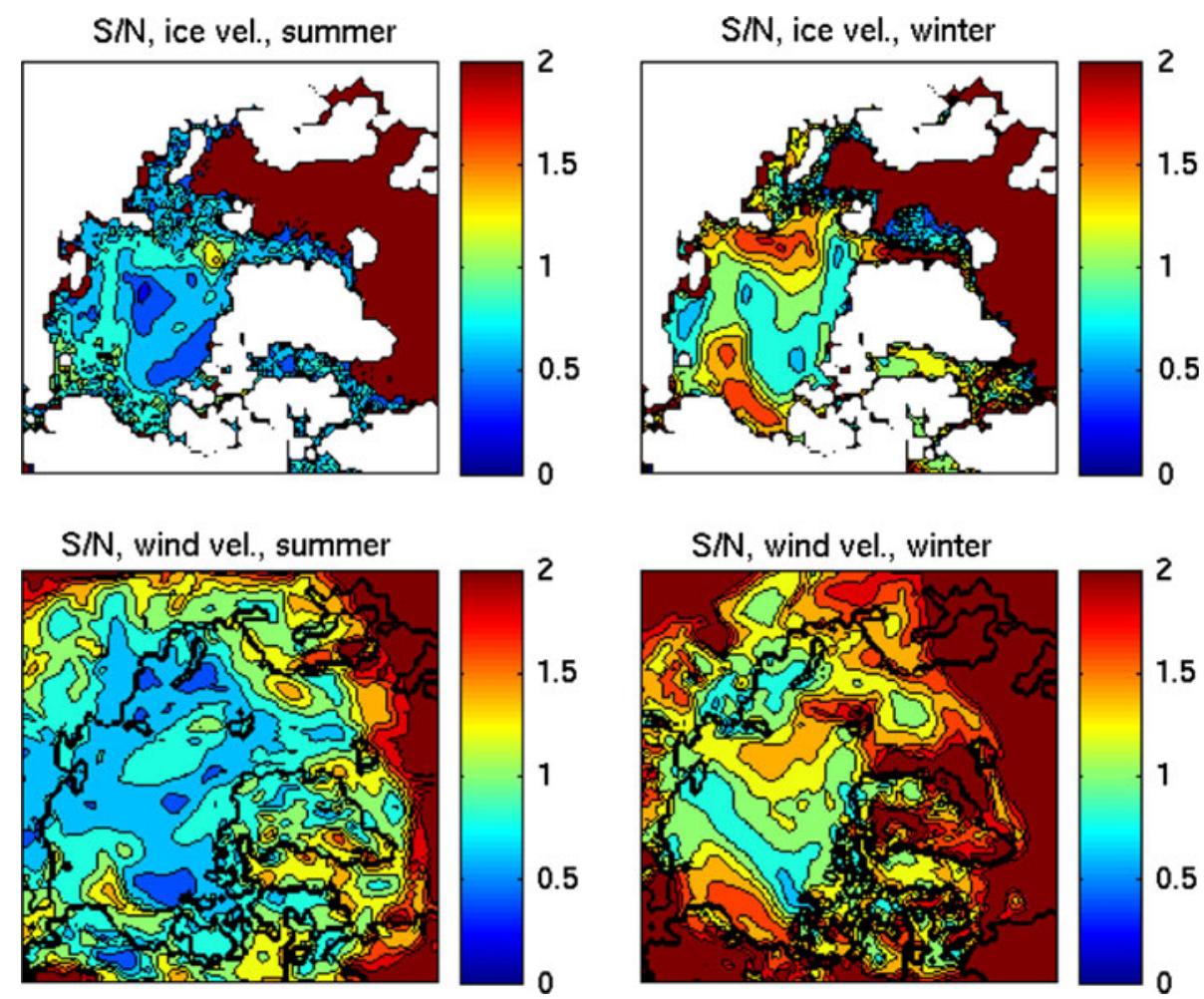
Fig. 17 Internal (left), external (center) variability of Arctic winter (JFM) long wave downward radiation (LWD) for the period $1980-2000$ in $\mathrm{W} / \mathrm{m}^{2}$, and signal/noise ratio (external/ internal) (right)
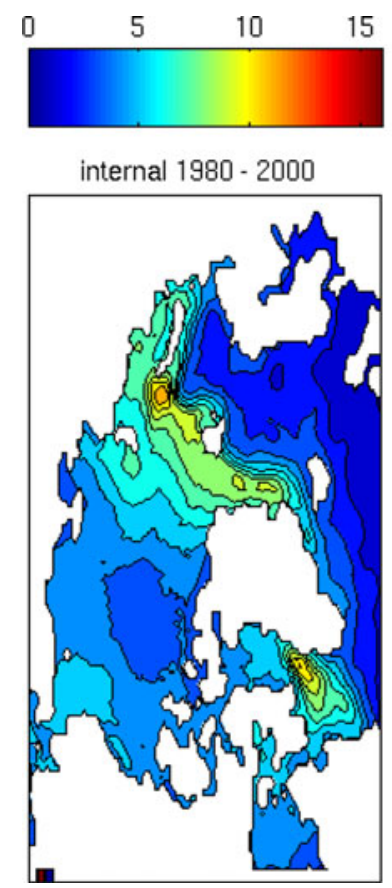
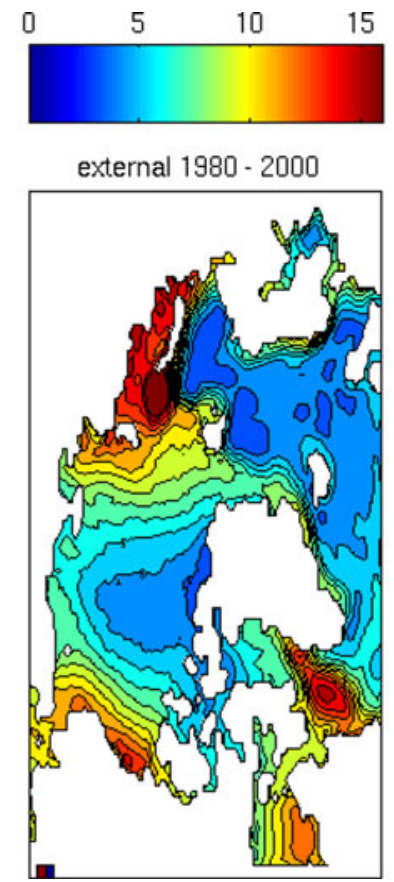

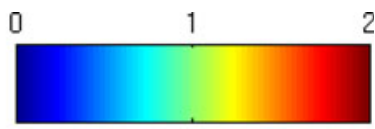

signal/noise $1980-2000$

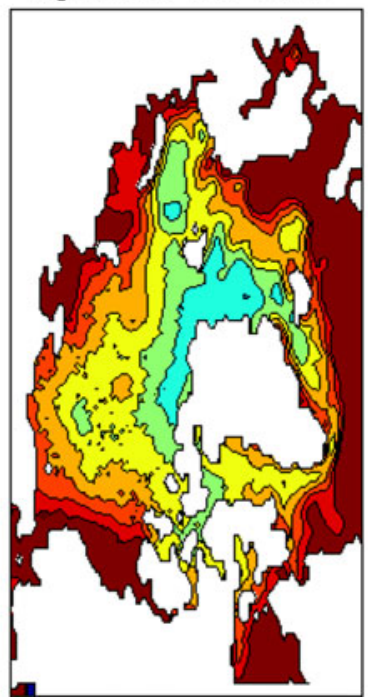

North Greenland coast and are deflected eastwards when facing the high rising ice sheet and meeting strong katabatic winds. This is illustrated in Fig. 18. The ensemble mean of winter SLP and surface air flow shows the typical downhill winds over Greenland and a convergence with the large scale circulation. For all ensemble members, the deflection is seen in a coastal band north and east of Greenland. This phenomenon explains the typical structures seen in the signal/noise ratios for T2m, LWD, ice thickness, and in the MLTF of wind direction. The effect of cold katabatic winds on air temperature at the coast is obvious. LWD is affected directly by the air temperature. Ice thickness can be influenced by offshore wind and the wind direction variability is due to the deflection. In further support of our hypothesis, Fig. 16 shows generally low $S / N$ ratios over Greenland during summer and over the northeastern Greenland coast. This suggests a dominance of internal variability in the Greenland surface winds.

\section{Summary and discussion}

This study explores the relative role of Arctic climate variability generated internally within the Arctic ("internal variability") and forced variability due to large scale conditions ("external variability"). The question is addressed by analyzing a mini-ensemble of simulations with the Arctic regional coupled ocean-ice-atmosphere model RCAO. Analyses are carried out based on monthly and seasonal means. The variability addressed here is interannual variability. This regional study give us an

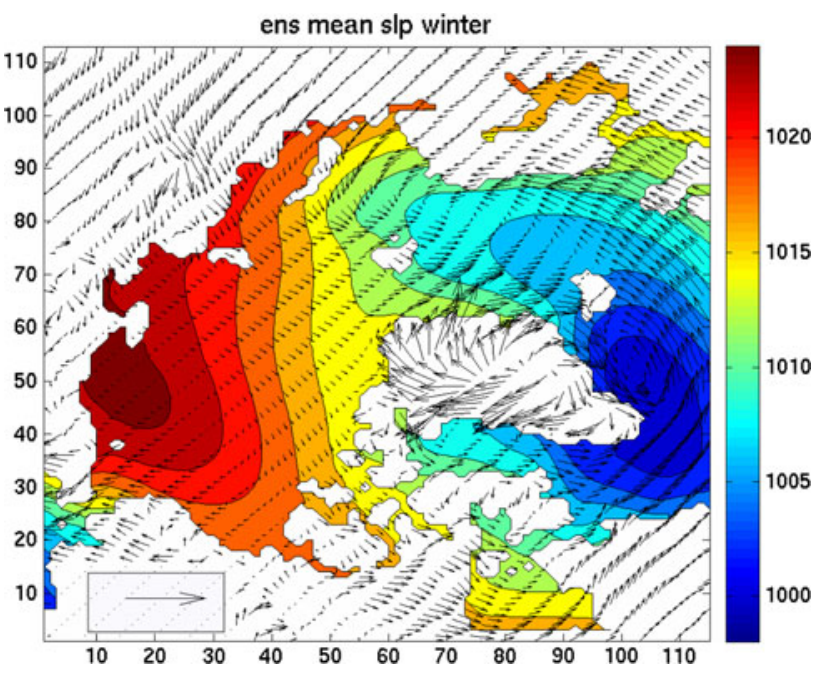

Fig. 18 Ensemble mean winter sea level pressure (SLP, in hPa) and wind field in $10 \mathrm{~m}$ height. The reference arrow in the lower left corner represents $10 \mathrm{~m} / \mathrm{s}$

impression of the magnitude of inherently unpredictable processes and lead to better understanding of limitations of the Arctic performance in global prediction systems.

Several climate variables and relations relevant for this study have been validated by comparison with observations. The seasonal mean fields of sea ice concentration agree well with observations in large parts of the Arctic. An empirical relation between sea ice extent and NAO index has been confirmed in the coupled model: higher than normal NAO index is associated with reduced sea ice extent. Furthermore, a positive NAO index is correlated with a reduced ice thickness at the ice edge and in the 
Barents Sea, Kara Sea, East-Siberian Sea and in the Chukchi Sea. During the analysis period 1980-2000, all ensemble members show a clear trend towards less ice. Three out of four ensemble members remarkably resemble the observed long-term trend of sea ice extent very closely.

Trends are conceptually part of the variability, but the patterns of influence (external or internal) are only marginally affected by a trend. This has been demonstrated for the case of sea ice thickness. Contrary to local sea ice concentration, the decreasing thickness trend is statistically significant and to a large degree controlled by external forcing at the outer boundaries of our regional model domain. Consequently, the role of internal processes for the thinning trend is small. We conclude that an Arctic-scale sea ice thickness trend can be derived with good skill if the large scale circulation and other physical conditions are given outside the Arctic.

Under recent climate conditions during the 1980s and 1990 s, we find that the external variability is stronger than the internal variability by a factor of 1-2 for most climate variables over most parts of the Arctic. A factor of 1 indicates equal importance of internal and external variability. External variability is naturally strongest close to the outer domain boundaries where the large scale forcing is applied, and decreasing towards the center of the model domain, whereby the Arctic pattern of the different influences depends very much on the climate variable in question and the processes determining that variable.

Internal variability can be limited during times. For the sea ice extent we have shown that robust results in terms of small differences within the ensemble can be achieved under the pressuring influence of certain large scale atmospheric circulation conditions. Such strong dependencies as e.g. between the NAO index and the intraensemble spread hold temporarily only. We have shown that a strong atmospheric surface pressure gradient anomaly between the Nordic Seas and the Kara Sea, as reflected in the positive phase of our 2nd EOF pattern of winter SLP, is supportive for a broad spread of simulated overall ice extents within the ensemble. This gives rise to weak predictability of sea ice extent. Vice versa, a reversed surface pressure gradient anomaly increases the predictability of sea ice extent. The first case is connected to southeasterly wind anomalies from Northern Scandinavia to Northern Greenland while the latter case reflects northerly wind anomalies. Similar to a positive NAO index with its increased cyclonic circulation component over the Arctic Ocean, northerly winds from the Arctic Ocean into the Nordic Seas favor increased sea ice export which constrains the ensemble towards more similar sea ice extents within the ensemble. This view is compatible with the nature of the Arctic dipole anomaly (DA) as described by $\mathrm{Wu}$ et al. (2006) in an analysis of winter SLP anomalies north of $70^{\circ} \mathrm{N}$ and sea ice export in a global coupled model. $\mathrm{Wu}$ et al. (2006) emphasize a strong influence of the DA (the 2nd EOF of SLP) on sea ice export, which is comparable to, or larger than the AO's (the 1st EOF of SLP) influence. Similar to our 2nd EOF, centers of action are located over the Nordic Seas and over the Siberian coastal area.

Our study addresses Arctic climate system predictability under the assumption of known large scale circulation outside a wider Arctic domain. That assumption is currently academic because the skill in interannual forecast of the large scale atmospheric circulation is small. This is especially true for AO/NAO oscillations. Thus we are asking the question: If we had a perfect multi-year forecast of the large scale ocean and atmosphere circulation outside the Arctic, to what extent would we be able to infer Arctic climate forecasts on a multi-annual timescale? In other words: what is the uncertainty of the Arctic in an interannual prediction due to Arctic non-linear interactive chaotic processes? The answer depends on the extent of internally generated processes, their degree of determinism and the externally forced variability. Dominance of external variability supports the task of prediction systems.

Our $S / N$ ratios of two-dimensional Arctic fields, defined as the ratio of external and internal variability, indicate the degree of potential predictability of a given variable. From the $S / N$ ratios we can conclude that on interannual time scales, the Arctic is far from determined by external processes solely. Although externally forced year-to-year variability is often stronger than internally generated variability, the latter cannot be neglected. In many cases, both types of variability show the same order of magnitude, or the internally generated variability is even dominating in certain areas. Thus, the interannual variability at the Arctic surface, as represented in our model under climate conditions of the 1980s and 1990s, gives a mixed picture of predictability with both internally and externally controlled areas.

Thickness trends are found to be largely externally forced. This is also true for thickness variability at the Russian and North American coasts and during summer in a region north of the Kara Sea. Patterns of external and internal ice thickness variability are largely agreeing with results from Mikolajewicz et al. (2005). T2M outside the region directly north and east of Greenland is externally dominated, as is ice velocity and wind velocity during winter in certain areas.

Internal variability is outweighing external variability in specific areas, identified by low $S / N$ fields. Low $S / N$ ratios are often found north of Greenland with an extension to the Fram Strait area and the Greenland Sea. This feature is especially prominent in the T2M and LWD winter $S / N$ fields. In some cases, that shape extends to a V-like 
signature of low $S / N$ in the central Arctic. Mostly, but less than always, these areas of relatively strong internal variability are connected to both low absolute internal and external variability.

A major reason for large areas of internally dominated variability north and east of Greenland is seen in the interaction between katabatic winds arising from the Greenland ice sheet and the large scale air circulation. Eastward deflection of large scale winds in the area in question and erratic components in the behaviour of cold katabatic winds at the surface of the Greenland ice sheet provide an explanation for internally caused interannual variability in surface air temperature, long wave downward radiation and wind direction. Erratic behavior of Greenland winds in our model is documented by internally dominated wind direction variability. The picture of strong sensitivity of katabatic winds to both large scale processes and small scale locally important processes with little relation to large scale processes is confirmed by high resolution simulation studies over Greenland. Klein et al. (2001) note a strong sensitivity of occurrence of katabatic flows to e.g. the representation of local cloud physics.

Summarizing the origins of internal variability, we have identified the state of the DA to be either supportive or depressant for the overall Arctic sea ice extent internal variability. On the other hand side, erratic Greenland winds are likely responsible for internally controlled areas north and east of Greenland. Currently it remains unclear if these two processes are interconnected. This needs to be subject to further research.

Differences in sea ice extent between different ensemble members and between ensemble members and observations amount to up to $700,000 \mathrm{~km}^{2}$ (Fig. 3). This is the order of magnitude of the 2007 summer sea ice anomaly, indicating that such a strong anomaly might not be captured by a single forecast model run. Clearly, ensemble runs are necessary to capture the probability of a strong anomaly. In a warming climate with thinning ice cover, we speculate that local ice-atmosphere interplay modifies the effects of large scale forcing and might even be more important than during the 1980s and 1990s. This points to an even more interannually unpredictable system in the transition period towards less summer ice.

The amount of internally generated variability naturally depends on the size of the model domain. A smaller domain would prevent more of the internal variability and give increased predictability. This is indicated by comparison between different domain sizes of Arctic atmosphere models compiled within the Arctic Climate Model Intercomparison Project ARCMIP (Rinke et al. 2000). Mikolajewicz et al. (2005) present coupled model experiments in a configuration with a global ocean model and a regional atmosphere model in a domain larger than
RCAO's. In a four member ensemble, one member is passing a bifurcation point with the consequence of suppressed deep convection in the Labrador Sea. In our RCAO setup, no thresholds have been passed that could have triggered a different climate state. No bifurcations are seen in the RCAO ensemble, which is likely due to our smaller model domain.

No major regional warming events have been generated in our experiments. Bengtsson et al. (2004) suggest nonlinear processes to be responsible for the formation of a self-maintaining low atmospheric pressure anomaly explaining the "early warming" in the 1930s and 1940s. No such persisting anomaly was found in our runs. We speculate this could be either due to too short analysis periods (4 times 23 years), or again, due to a too small model domain, which limits consequences of the Arctic internally generated variability.

Our results concerning predictability depend on a single model set-up for the ensemble runs. Further work will test the robustness of our findings with respect to the model configuration. Major remaining questions are the dependence of results on sea ice parameterizations and cloudradiation formulations. It will also be interesting to test our findings under a generally warmer climate with thinner sea ice, and with higher numerical resolution of interaction processes.

Acknowledgments This work has been made possible by support of the Rossby Centre at the Swedish Meteorological and Hydrological Institute (SMHI) together with the EU project DAMOCLES. The DAMOCLES project is financed by the European Union in the 6th Framework Programme for Research and Development. We are especially grateful for the long term development effort by the Rossby Centre/SMHI staff, invested into the regional models RCA and RCO which form the base for RCAO. We also thank Dr. Torben Königk for valuable comments to the manuscript.

Open Access This article is distributed under the terms of the Creative Commons Attribution Noncommercial License which permits any noncommercial use, distribution, and reproduction in any medium, provided the original author(s) and source are credited.

\section{References}

Bengtsson L, Semenov VA, Johannessen OM (2004) The early twentieth-century warming in the Arctic-a possible mechanism. J Clim (October):4045-4057. doi:10.1175/1520-0442 (2004) $017<4045$ :TETWIT $>2.0$. CO;2

Brigitte Knopf, B (2006) On intrinsic uncertainties in earth system modelling $\mathrm{PhD}$ thesis, Universität Potsdam

Cavalieri DJ, Parkinson CL, Vinnikov KY (2003) 30-year satellite record reveals contrasting Arctic and Antarctic decadal sea ice variability. Geophys Res Lett 30(18):1970. doi:10.1029/ 2003GL018031

Döscher R, Willen U, Jones C, Rutgersson A, Meier HEM, Hansson U (2002) The development of the coupled ocean-atmosphere model RCAO. Boreal Environ Res 7:183-192 
ETOPO5 (1988) Data announcement 88-MGG-02, digital relief of the surface of the earth. NOAA, National Geophysical Data Center, Boulder

Hilmer M, Jung T (2000) Evidence for recent change in the link between the North Atlantic Oscillation and Arctic sea ice export. Geophys Res Lett 27(7):989-992. doi:10.1029/1999GL010944

Holland MM (2003) The North Atlantic Oscillation in the CCSM2 and its influence on Arctic climate variability. J Clim 16:2767-2781. doi:10.1175/1520-0442(2003)016<2767:TNAOOI $>2.0 . C O ; 2$

Holland MM, Bitz CM, Tremblay B (2006) Future abrupt reductions in the summer Arctic sea ice. Geophys Res Lett. doi:10.1029/ 2006GL028024

Hu A, Rooth C, Bleck R, Deser C (2002) NAO influence on sea ice extent in the Eurasian coastal region. Geophys Res Lett 29(22):2053-2054. doi:10.1029/2001GL014293

Hunke EC, Dukowicz JK (1997) An elastic-viscous-plastic model for sea ice dynamics. J Phys Oceanogr 27:1849-1867. doi:10.1175/ 1520-0485(1997)027<1849:AEVPMF>2.0.CO;2

IPCC 2007: Climate change 2007-the physical science basis (ISBN13: 9780521705967). Cambridge University Press

Jones CG, Willén U, Ullerstig A, Hansson U (2004a) The Rossby Centre Regional Atmospheric Climate Model part I: model climatology and performance for the present climate over Europe. Ambio 33(4/5):199-210

Jones CG, Wyser K, Ullerstig A, Willén U (2004b) The Rossby Centre Regional Atmospheric Climate model part II: application to the Arctic climate. Ambio 33(4/5):211-220

Keenlyside NS, Latif M, Jungclaus J, Kornblueh L, Roeckner E (2008) Advancing decadal-scale climate prediction in the north Atlantic sector. Nature 453:84-88. doi:10.1038/nature06921

Kjellström E, Bärring L, Gollvik S, Hansson U, Jones C, Samuelsson P, Rummukainen M, Ullerstig A, Willén U, Wyser K (2005) A 140-year simulation of European climate with the new version of the Rossby Centre regional atmospheric climate model (RCA3). SMHI reports meteorology and climatology RMK No. 108, $54 \mathrm{pp}$

Klein T, Heinemann G, Bromwich DH, Cassano JJ, Hines KM (2001) Mesoscale modeling of katabatic winds over Greenland and comparisons with AWS and aircraft data. Meteorol Atmos Phys 78:115-132. doi:10.1007/s007030170010

Koenigk T, Mikolajewicz U, Haak H, Jungclaus J (2006) Variability of Fram Strait sea ice export: causes. Impacts and feedbacks in a coupled climate model. Clim Dyn 26(1):17-34

Køltzow M, (2007) The effect of a new snow and sea ice albedo scheme on regional climate model simulations. J Geophys Res 112:D07110. doi:10.1029/2006JD007693

Meier HEM, Döscher R, Faxén T (2003) A multiprocessor coupled ice-ocean model for the Baltic Sea: application to salt inflow. J Geophys Res 108(C8):3273. doi:10.1029/2000JC000521

Mikolajewicz U, Sein DV, Jacob D, Königk T, Podzun R, Semmler T (2005) Simulating Arctic sea ice variability with a coupled regional atmosphere-ocean-sea ice model. Meteorologische Zeitschrift, 14(6), 1 December 2005, pp 793-800(8)

Neter J, Wassermann W, Whitmore GA, (1988) Applied statistics, 3rd edn, ISBN: 0205103286

Phelps MW, Kumar A, O'Brien JJ (2004) Potential predictability in the NCEP CPC dynamical seasonal forecast system. J Clim 17(19):3775-3785

Pohlmann H, Botzet M, Latif M, Roesch A, Wild M, Tschuck P (2004) Estimating the decadal predictability of a coupled AOGCM. J Clim 17:4463-4472

Polyakov I, Bekryaev RV, Alekseev GV, Bhatt US, Colony RL, Johnson MA, Makshtas AP, Walsh D (2003) Variability and trends of air temperature and pressure in the maritime Arctic, 1875-2000. J Clim 16(12):2067-2077
Prange M (2003) Einfluss arktischer Süßwasserquellen auf die Zirkulation im Nordmeer und im Nordatlantik in einem prognostischen Ozean-Meereis-Modell Rep Polar Mar Res, 468, AWI, Bremerhaven, Germany

Rayner NA, Parker DE, Horton EB, Folland CK, Alexander LV, Rowell DP, Kent EC, Kaplan A (2003) Global analyses of sea surface temperature, sea ice, and night marine air temperature since the late nineteenth century. J Geophys Res 108(D14):4407. doi:10.1029/2002JD002670

Rigor IG, Wallace JM, Colony RL (2002) Response of Sea Ice to the Arctic Oscillation. J Clim 15(18):2648-2668

Rinke A, Dethloff K (2000) On the sensitivity of a regional Arctic climate model to initial and boundary conditions. Clim Res 14(2):101-113

Rinke A, Lynch AH, Dethloff K (2000) Intercomparison of Arctic regional climate simulations: case studies of January and June 1990. J Geophys Res 105(D24):29669-29683

Rodi W (1980) Turbulence models and their application in hydraulics-a state-of-the-art review. Int Assoc Hydraul Res, Delft, Netherlands, $104 \mathrm{pp}$

Rothrock DA, Zhang J, Yu Y (2003) The Arctic ice thickness anomaly of the 1990s: a consistent view from observations and models. J Geophys Res 108(C3):30-83. doi:10.1029/2001JC001208

Samuelsson P, Gollvik S, Ullerstig A (2006) The land-surface scheme of the Rossby Centre regional atmospheric climate model (RCA3). Report in meteorology 122, SMHI. SE-601 76 Norrköping, Sweden

Semtner AJ (1976) A model for the thermodynamic growth of sea ice in numerical investigations of climate. J Phys Oceanogr 6:27-37

Serreze MC, Holland MM, Stroeve J (2007) Perspectives on the Arctic's shrinking sea-ice cover. Science 315(5818):1533-1536. doi:10.1126/science.1139426

Sorteberg A, Furevik T, Drange H, Kvamst $\varnothing$ NG (2005) Effects of simulated natural variability on Arctic temperature projections. Geophys Res Lett 32:LI8708. doi:10.1029/2005GL023404

Steele M, Morley R, Ermold W (2001) PHC: a global ocean hydrography with a high quality Arctic Ocean. J Clim 14:20792087

Stevens DP (1990) On open boundary conditions for three dimensional primitive equation ocean circulation models. Geophys Astrophys Fluid Dyn 51:103-133

Sutton RT, Allen MR (1997) Decadal predictability in the North Atlantic. Nature 388:563-567

Undén P, Rontu L, Järvinen H, Lynch P, Calvo J, Cats G, Cuaxart J, Eerola K, Fortelius C, Garcia-Moya JA, Jones C, Lenderlink G, McDonald A, McGrath R, Navascues B, Nielsen NW, Ødegaard V, Rodriguez E, Rummukainen M, Rööm R, Sattler K, Sass BH, Savijärvi H, Schreur BW, Sigg R, The H, Tijm A (2002) HIRLAM-5 scientific documentation, HIRLAM-5 project. Available from SMHI, S-601767 Norrköping, Sweden

Uppala SM, Kållberg PW, Simmons AJ, Andrae U, da Costa Bechtold V, Fiorino M, Gibson JK, Haseler J, Hernandez A, Kelly GA, Li X, Onogi K, Saarinen S, Sokka N, Allan RP, Andersson E, Arpe K, Balmaseda MA, Beljaars ACM, van de Berg L, Bidlot J, Bormann N, Caires S, Chevallier F, Dethof A, Dragosavac M, Fisher M, Fuentes M, Hagemann S, Hólm E, Hoskins BJ, Isaksen L, Janssen PAEM, Jenne R, McNally AP, Mahfouf J-F, Morcrette J-J, Rayner NA, Saunders RW, Simon P, Sterl A, Trenberth KE, Untch A, Vasiljevic D, Viterbo P, Woollen J (2005) The ERA-40 re-analysis. Quart J R Meteorol Soc 131:2961-3012. doi:10.1256/qj.04.176

Valcke S, Redler R (2006) OASIS4 user guide (OASIS4_0_2). PRISM support initiative report no. 4, $60 \mathrm{pp}$

Vancoppenolle, M, Fichefet T, Goosse H, Bouillon S, Beatty CK, Morales Maqueda MA (2008) LIM3, an advanced sea-ice model 
for climate simulation and operational oceanography. Mercator Newslett 28

Wang M, Overland JE, Kattsov V, Walsh JE, Zhang X, Pavlova T (2007) Intrinsic versus forced variation in coupled climate model simulations over the Arctic during the twentieth century. J Clim 20(6):1093-1107

Webb DJ, Coward AC, de Cuevas BA, Gwilliam CS (1997) A multiprocessor ocean circulation model using message passing. J Atmos Oceanic Technol 14:175-183

Wu B, Wang J, Walsh JE (2006) Dipole anomaly in the winter Arctic atmosphere and its association with Arctic sea ice motion. J Clim 19(2):210-225. doi:10.1175/JCLI3619.1
Zhang X, Walsh JE (2006) Toward a seasonally ice-covered Arctic Ocean: scenarios from the IPCC AR4 model simulations. J Clim 19:1730-1747

Zhou S, Miller AJ, Wang J, Angell JK (2001) Trends of NAO and AO and their associations with stratospheric processes. Geophys Res Lett 28:4107-4110

Zwiers FW (1987) A potential predictability study conducted with an atmospheric general circulation model. Mon Weather Rev 115:2957-2974 